\title{
ӘImpacts of Hydrometeor Drift on Orographic Precipitation: Two Case Studies of Landfalling Atmospheric Rivers in British Columbia, Canada
}

\author{
Ruping Mo AND MElinda M. BRUgMan \\ National Laboratory-West, Environment and Climate Change Canada, Vancouver, British Columbia, Canada \\ JASON A. MILBRANDT \\ Meteorological Research Division, Environment and Climate Change Canada, Dorval, Quebec, Canada \\ James Goosen, QuAnZhen Geng, Christopher Emond, And JonAthan BAU \\ Pacific Storm Prediction Centre, Environment and Climate Change Canada, Vancouver, British Columbia, Canada \\ AMIN ERFANI \\ Canadian Meteorological Centre, Environment and Climate Change Canada, Dorval, Quebec, Canada
}

(Manuscript received 18 October 2018, in final form 6 June 2019)

\begin{abstract}
Two severe winter storms in 2016 and 2017 caused by landfalling atmospheric rivers over British Columbia (BC) are investigated in this study. Our main concern is the impact of hydrometeor drift on the orographic precipitation. It is shown that the dominant contribution to the windward orographic precipitation was from the horizontal moisture convergence. The precipitation distributions across southern $\mathrm{BC}$ were also influenced by the convergence/divergence of condensed water due to the wind-driven effect on hydrometeors. Observed hourly and daily precipitation amounts are used to verify the performances of three Canadian numerical weather prediction systems. Our results indicate that these operational systems were capable of predicting the general features of orographic precipitation in BC. However, the two coarse-resolution systems used a diagnostic precipitation scheme that does not fully simulate the hydrometeor drift process. The High-Resolution Deterministic Prediction System (HRDPS) with a prognostic precipitation scheme was substantially more accurate and skillful in predicting the upwind precipitation as well as the spillover of precipitation on the leeward slopes for these two storms. There was evidence suggesting that the spillover effect was overpredicted by the HRDPS due to a systematic bias originating in the model microphysics. This problem has been improved in the current HRDPS with a new microphysics scheme. Based on our atmospheric water balance analysis, we also proposed two postprocessing schemes that could be applied to improve the quantitative precipitation forecasts of the diagnostic precipitation schemes.
\end{abstract}

\section{Introduction}

Precipitation over complex terrain is one of the most difficult meteorological phenomena to measure, model, and predict. Heavy orographic precipitation can trigger severe floods, landslides, and avalanches. With insufficient rain gauge density and radar coverage in a

D Denotes content that is immediately available upon publication as open access.

Corresponding author: Dr. R. Mo, ruping.mo@canada.ca mountainous region, operational forecasters have to rely heavily on the guidance of numerical weather prediction (NWP) systems for their routine quantitative precipitation forecasts (QPFs). However, the raw model QPFs over complex terrain are still prone to large errors, mainly because the relative importance of orographic forcing mechanisms is neither fully understood nor adequately represented by the operational NWP systems (Ibbitt et al. 2000; Wulfmeyer et al. 2011; Geng et al. 2012; Milbrandt et al. 2014; Bližńák et al. 2017). In addition, finescale precipitation processes are often parameterized in some low-resolution models, adding 
potential sources of systematic errors in the raw model QPFs. Therefore, some statistical calibration or postprocessing methods are often applied to correct model biases and produce more reliable model guidance for operational forecasting applications (e.g., McCollor and Stull 2008; Robertson et al. 2013; Li et al. 2017). There are also contemporary modeling techniques, such as artificial and computational intelligence methods, which can be combined with the model QPFs and applied to hydrological forecasts over mountainous regions (Cheng et al. 2005; Wu and Chau 2011; Taormina et al. 2015).

One of the difficulties with predicting orographic precipitation is related to the wind-driven effect on the condensed water and ice droplets (hydrometeors) in the atmosphere (Hobbs et al. 1973; Browning et al. 1974; Chu et al. 1997; Sinclair et al. 1997; Ralph et al. 2003; Geng et al. 2012). Over flat terrain, the flow and precipitation are generally uniform across a large spatial domain, and the wind-driven phenomenon is a simple advective process that carries the falling hydrometeors downstream about a distance proportional to the mean wind speed. The impacts of hydrometeor drift on the precipitation distribution are generally minor thanks to the weak convergence or divergence of condensed water in the atmosphere. In mountainous regions, the orographic condensation due directly to the lifting of moist air up the mountain slopes usually has a complicated spatial distribution. The wind-driven effect can lead to the "spillover" phenomenon, which refers to a situation when the hydrometeors forming over the upwind side are advected downwind to fall as precipitation in the rain-shadow region in the leeward side (Fletcher 1951; Elliott and Hovind 1964; Browning et al. 1974, 1975; Hill et al. 1981; Tuller 1987; Sinclair et al. 1997; Chater and Sturman 1998; Medina et al. 2005; Zängl and Hornsteiner 2007; Brugman and MacDonald 2008; Underwood et al. 2009; Siler et al. 2013; Mass et al. 2015; Siler and Durran 2016). Previous studies have demonstrated that the hydrometeor drift and spillover over complex terrain are very sensitive to the atmospheric stratification, vertical moisture and wind profiles, freezing level height, and subtle interactions between airflow dynamics and cloud microphysics (Colle 2004; Zängl 2005, 2007; Wastl and Zängl 2010; Kaplan et al. 2012; Stoelinga et al. 2013; Siler and Roe 2014; Siler and Durran 2016). Operational forecasters expect that these complicated issues are handled adequately by the NWP systems. Otherwise the model QPFs in mountainous regions should be reevaluated and adjusted accordingly.

In this paper we present two case studies of winter heavy precipitation events to illustrate the major impacts of hydrometeor drift on the operational weather forecasting in complex terrain. Our main goals are to acquire a better understanding of the temporal-spatial variability of orographic precipitation under similar circumstances, and to help operational forecasters develop a robust conceptual model for their prognostic assessment of orographic precipitation. The two selected events occurred in the Canadian western province of British Columbia (BC) during 26-28 January 2016 and 16-18 January 2017, respectively. They were the typical severe winter storms that can be attributed to a phenomenon called "atmospheric river" (AR): a long, narrow, and transient corridor of strong water vapor transport (Newell et al. 1992; Zhu and Newell 1994, 1998; Ralph et al. 2004, 2017, 2019; Mo and Lin 2019; American Meteorological Society 2019). A snapshot of the January 2016 storm is shown in Fig. 1. The elongated cloud band in the satellite imagery indicates a strong AR that originated in the subtropical Northwest Pacific. Its landfall produced heavy rain in many BC coastal communities, especially on Vancouver Island where widespread floods occurred (Bell and Harnett 2016; Brian 2016; Titian 2016). This AR also penetrated inland and impacted the Rocky Mountains. It was partially blamed for the massive avalanche near McBride, BC on 29 January 2016 that killed five snowmobilers (Lindsay 2016). Because of some uncertainty related to hydrometeor drift in the NWP guidance, this winter storm posed a significant challenge to operational meteorologists at the Pacific Storm Prediction Centre. A similar scenario was seen in the January 2017 storm. The similarity of these two storms allows a better assessment of hydrometeor drift in our study.

The major forecast challenges for these two winter storms were to correctly identify regions with heavy precipitation potential and issue useful timely warnings to the public and decision makers accordingly. The forecast guidance provided by the three operational NWP systems of Environment and Climate Change Canada (ECCC) contained large uncertainty in the medium-range forecasts (up to seven days) for these storms. In the short-range forecasts (up to two days), there were some substantial differences in the model QPF distributions. In both cases, some of the model discrepancy can be attributed to the impact of hydrometeor drift, which was explicitly predicted by a high-resolution (2.5-km horizontal grid spacing) system that uses a detailed bulk microphysics scheme with prognostic precipitation (i.e., hydrometeors are advected horizontally by the dynamical model), but not by the other two lower-resolution (25and $10-\mathrm{km}$ grid spacing) systems that use a simple condensation scheme with diagnostic precipitation 


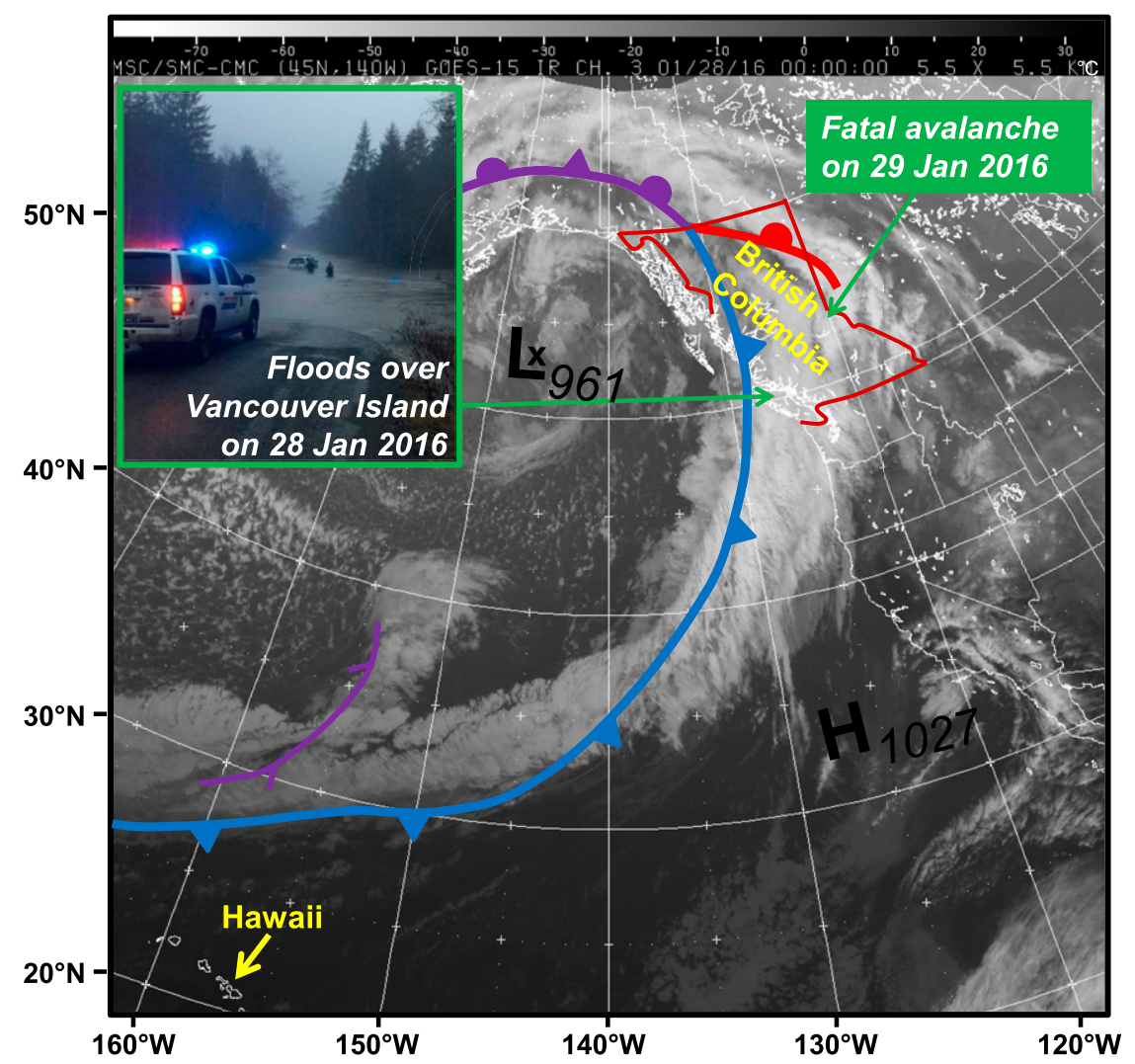

FIG. 1. Infrared imagery of weather satellite and frontal analysis showing an atmospheric river making landfall in British Columbia at 0000 UTC 28 Jan 2016. Evidence of flooding over Vancouver Island is shown in a photograph taken by Rose-Ann Michael around the same time (Titian 2016).

(i.e., hydrometeors are assumed to fall instantly to the ground as precipitation, with no further horizontal advection). For example, the first storm produced only $28 \mathrm{~mm}$ of rainfall at the Vancouver International Airport for the 24-h period ending at 1800 UTC 28 January 2016. The high-resolution model gave a QPF of $24 \mathrm{~mm}$, while the amounts predicted by the other two models were $85 \mathrm{~mm}$ and $74 \mathrm{~mm}$, respectively. Note that the public rainfall warning criterion for Metro Vancouver is $50 \mathrm{~mm}$ within a 24 -h period. For the high-resolution model system, the predicted amount for this station was slightly less than the observation. Although this is not much of a difference for this storm, it is not clear whether the hydrometeor drift process was correctly predicted by the model microphysics scheme (Garvert et al. 2005a,b; Milbrandt et al. 2008, 2010). These important practical and research questions will be addressed and some possible solutions will be explored in the present study. We also intend to help operational forecasters better understand the role of landfalling ARs in modulating extreme precipitation events over complex terrain.
The remainder of this paper is organized as follows. Section 2 provides an overview of the atmospheric water balance requirements and their implications in the orographic precipitation analysis. The physical geography of southern BC, data, and NWP systems used in this study are described in section 3 . The two AR-enhanced winter storms and the corresponding model predictions are analyzed in sections 4 and 5, respectively. Concluding remarks are given in section 6 .

\section{The atmospheric water balance and precipitation}

Heavy precipitation requires sufficient moisture supply in the atmosphere and some mechanisms to lift the moisture for condensation. Because of the conservation of water in the atmosphere, any local change of water content can only occur through the addition or subtraction of water in vapor, liquid, and/or ice phases. Therefore, at an instant $t$ and a given spatial location $(x, y, p)$, the general balance equation for the atmospheric water content can be expressed as follows (see Peixoto 1973): 


$$
\begin{aligned}
& {\left[\frac{\partial q}{\partial t}+\nabla \cdot\left(q \mathbf{V}_{h}\right)+\frac{\partial(q \omega)}{\partial p}\right]} \\
& +\left[\frac{\partial q_{c}}{\partial t}+\nabla \cdot\left(q_{c} \mathbf{V}_{h}\right)+\frac{\partial\left(q_{c} \omega_{c}\right)}{\partial p}\right]=0,
\end{aligned}
$$

where $q$ is the specific humidity, $\mathbf{V}_{h}$ is the horizontal wind vector on an isobaric level, $\nabla \cdot=\partial / \partial x+\partial / \partial y$ is a horizontal operator, $p$ is the pressure used as vertical coordinate, $\omega=d p / d t$ is the vertical $p$ velocity, $q_{c}$ is the specific water in the condensed (liquid and/or solid) phase, and $\omega_{c}$ is the local mean vertical velocity of hydrometeors.

Equation (1) can be vertically integrated from Earth's surface to the top of atmosphere. The resulting equation can be given as

$$
P=E-\partial\left(W+W_{c}\right) / \partial t \underbrace{-\nabla \cdot\left(\mathbf{Q}+\mathbf{Q}_{c}\right)}_{+\left(C_{\mathrm{wv}}+C_{\mathrm{cw}}\right)},
$$

where $C_{\mathrm{wv}} \equiv-\nabla \cdot \mathbf{Q}, C_{\mathrm{cw}} \equiv-\nabla \cdot \mathbf{Q}_{c}$, and

$$
\left(W, W_{c}, \mathbf{Q}, \mathbf{Q}_{c}\right)=g^{-1} \int_{p_{t}}^{p_{b}}\left(q, q_{c}, q \mathbf{V}_{h}, q_{c} \mathbf{V}_{h}\right) d p .
$$

In the above equations, $g$ is the acceleration due to gravity; $p_{b}$ and $p_{t}$ are pressures at the base and top of the air column, respectively; $P$ and $E$ are the rates of liquidequivalent precipitation and evaporation measured at Earth's surface, respectively; $W$ is the vertically integrated water vapor (IWV; also known as the precipitable water); $W_{c}$ is the integrated condensed water (ICW); $\mathbf{Q}$ is the integrated water vapor flux (IWVF); and $\mathbf{Q}_{c}$ is the integrated condensed water flux (ICWF). The magnitude of IWVF, $|\mathbf{Q}|$, is often referred to as the integrated vapor transport (IVT) in the atmospheric river analysis. For convenience, we also use $C_{\mathrm{wv}}$ and $C_{\mathrm{cw}}$ to represent the convergences of IWVF and ICWF, respectively. Some studies use a simpler version of Eq. (2) by ignoring the tendency and transport of condensed water (e.g., Palmén and Newton 1969; Trenberth and Guillemot 1998; Moore and Holdsworth 2007; Cordeira et al. 2013). Note that each term in Eq. (2) is expressed in a unit of mass per unit area per unit time. If this unit is given as kilograms per square meter per second $\left(\mathrm{kg} \mathrm{m}^{-2} \mathrm{~s}^{-1}\right)$, then it is equivalent to a precipitation rate in millimeters per second $\left(\mathrm{mm} \mathrm{s}^{-1}\right)$, assuming a water density of $1000 \mathrm{~kg} \mathrm{~m}^{-3}$.

Equation (2) decomposes the precipitation rate into five interrelated components. When the equation is averaged over a large area and for a long period, the balance is often dominated by precipitation $P$, evaporation $E$, and moisture convergence $C_{\mathrm{wv}}$ (e.g., Palmén and Newton 1969). For a synoptic-scale heavy precipitation event, $P$ and $C_{\mathrm{wv}}$ become the dominant components in Eq. (2), and the contribution from local evaporation is often negligible (e.g., Mo and Lin 2019). When a large amount of moisture converges into an unsaturated air column $\left(C_{\mathrm{wv}}>0\right)$, the immediate consequence is a rapid increase of precipitable water $(\partial W / \partial t>0)$. For precipitation to occur, some physical mechanisms may be required to set up the vertical motion necessary to produce condensation, which lead to $\partial W / \partial t<0$ and $\partial W_{c} / \partial t>0$. A fraction or all of the condensed water may not fall straight down to the surface as local precipitation. Some condensed water droplets may either float in the air as cloud, evaporate/sublimate in the subcloud layer, or be advected out of the air column by strong winds. Note that, although the hydrometeor drift is an advective process, its net contribution to precipitation at a given location is related to the difference between influx and outflux of hydrometeors in the air column aloft. This difference is measured by the convergence of ICWF $\left(C_{\mathrm{cw}}\right)$. This term can be at times as important as the convergence of IWVF $\left(C_{\mathrm{wv}}\right)$, or at least as large as $\partial W / \partial t$, as pointed out by Peixoto (1973). Under such circumstances, the impact of hydrometeor drift cannot be disregarded. Some applications of Eq. (2) in the AR analysis will be illustrated in section 4 .

\section{Geography, data, and NWP systems}

\section{a. Physical geography in southern $B C$}

As shown in Fig. 2, there are four major mountain ranges in southern BC: 1) the Vancouver Island Ranges, 2) the Coast-Cascade Mountains, 3) the Columbia Mountains, and 4) the Rocky Mountains. The Lower Mainland, which includes Metro Vancouver and the Lower Fraser Valley, is the most populous area (about $60 \%$ of the provincial total population). The climate in coastal $\mathrm{BC}$ is dominated by the onshore flow of moist Pacific airstreams, with the windward outer coast of Vancouver Island receiving the greatest precipitation amounts. Some of the most severe rainfall events in this region can be attributed to landfalling ARs (Mo 2016; Cruickshank 2019). The eastern side of the Vancouver Island Ranges, on the other hand, has a less rainy climate; the Olympic Mountains in Washington State also act as a barrier to marine air masses traveling through coastal BC, leaving some regions, including the southwestern section of Metro Vancouver, in its rain shadow (Hare and Thomas 1979; Lange 1998).

The Coast-Cascade Mountains act as the second major barrier to the Pacific air masses, leaving the $\mathrm{BC}$ interior with a much drier and more continental climate. This is particularly true in the southwestern interior, 

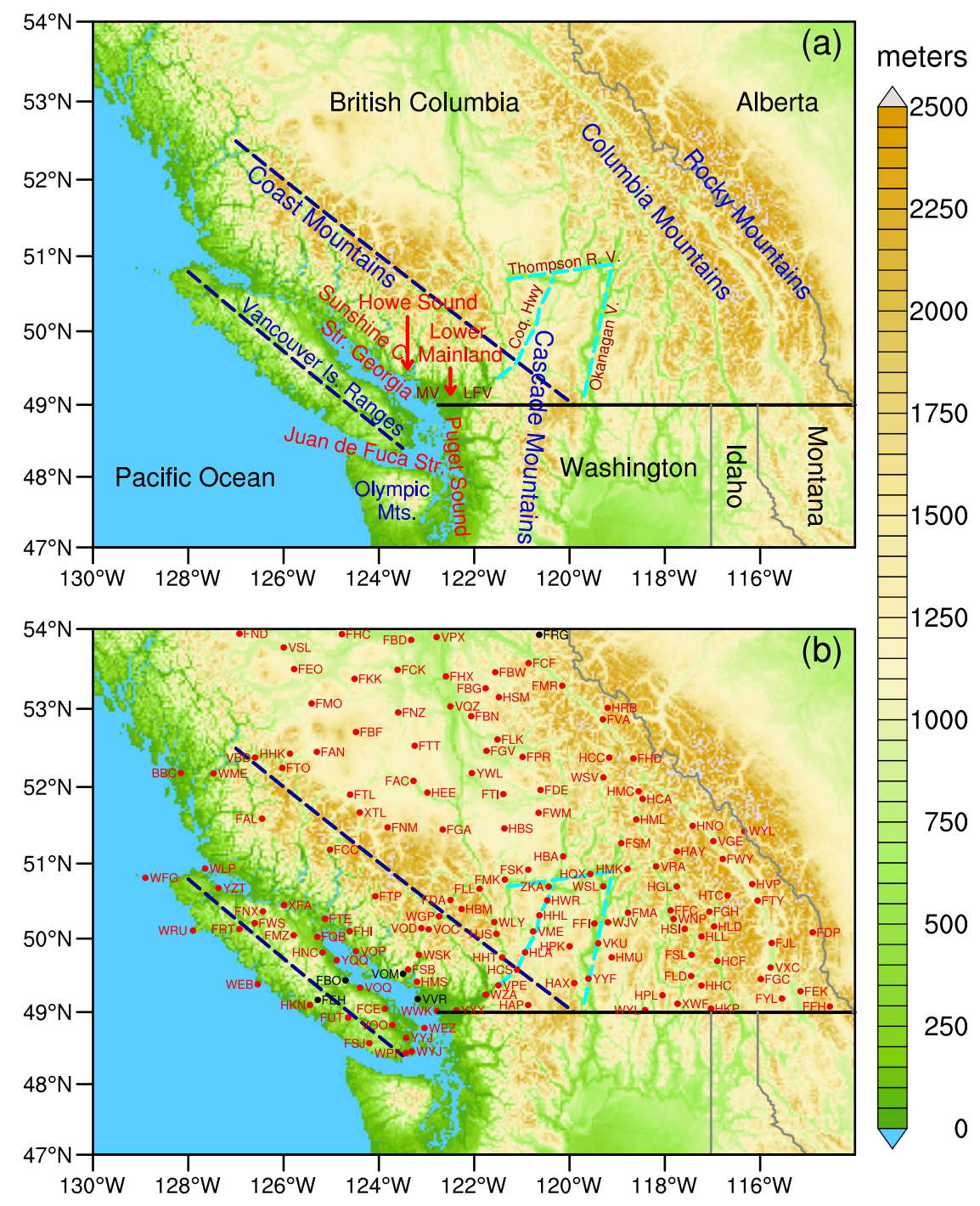

FIG. 2. (a) Topographical features across southern British Columbia. Lower Mainland consists of Metro Vancouver (MV) and the Lower Fraser Valley (LFV). The blue dashed lines are drawn to indicate the approximate crest locations of the Vancouver Island Ranges and the Coast-Cascade Mountains. The cyan dashed lines correspond to the Thompson River Valley, the Okanagan Valley, and the Coquihalla Highway, respectively. These dashed lines also appear in some other figures for geo-reference. (b) Locations and identifiers of 151 weather stations, from which hourly meteorological observations are available for this study. Some of the three-letter identifiers were defined by the Pacific Storm Prediction Centre for internal use.

including the Thompson River Valley and the Okanagan Valley. The eastward processions of some Pacific disturbances may bring cloud and precipitation to the region. However, amounts are usually small in the valleys due to the rain-shadow effect. Areas farther east on the windward slopes of the Columbia Mountains tend to experience heavier precipitation.

\section{b. Observed precipitation data}

Observed precipitation data were collected from 176 weather stations across southern BC. The locations and three-letter identifiers of 151 weather stations are plotted in Fig. 2b. The other 25 stations will be indicated in two zoomed maps later. These weather stations were managed by several agents, including ECCC, the BC Wildfire Service (station IDs starting with "F"), and the BC Ministry of Transportation and Infrastructure (stations IDs starting with " $\mathrm{H}$ "). Most of these precipitation data were automatically measured. Given the challenges related to the measurement of solid precipitation (e.g., Rasmussen et al. 2012), some autostations with a tipping-bucket gauge 
cannot provide reliable precipitation data when the station temperature is below or near the freezing point. Wind is another important factor that can reduce catch efficiency if the gauge is not properly shielded and conditions are very windy. Our selected precipitation data were validated and double checked to minimize errors associated with these problems. In particular, some autostations reported hourly precipitation amount increasing rapidly when temperature increased across the freezing mark. These questionable observations were not used in this study.

\section{c. The NWP systems}

Meteorological data from the three operational NWP systems of ECCC are also used to analyze the two storms. These models are 1) the Global Deterministic Prediction System (GDPS-25km) operating on a YinYang grid with horizontal grid spacing varying from $17 \mathrm{~km}$ to $25 \mathrm{~km}$ (Côté et al. 1998; Girard et al. 2014; Qaddouri et al. 2015), 2) the 10-km Regional Deterministic Prediction System (RDPS-10km; Caron et al. 2016), and 3) the 2.5-km High-Resolution Deterministic Prediction System (HRDPS-2.5km; Milbrandt et al. 2016). All of these systems use the Global Environmental Multiscale (GEM) model of ECCC (Côté et al. 1998; Girard et al. 2014). Operational meteorologists across Canada rely heavily on the guidance of these NWP systems in their weather forecasting and warning processes.

In the GDPS- $25 \mathrm{~km}$ and RDPS-10km, condensation and precipitation are represented in a similar way, with the MoisTKE scheme for cloudy boundary layer (Mailhot et al. 2006), the Kain-Fritsch scheme (Kain 2004) for deep convection, the Kuo transient scheme (Kuo 1974; Bélair et al. 2005) for shallow convection, and the modified Sundqvist scheme (Sundqvist 1978; Pudykiewicz et al. 1992) for gridscale condensation. The Sundquist scheme advects nonsedimenting condensate (cloud droplets/ice crystals), but it does not advect precipitating hydrometeors (rain/snow). It is assumed that the precipitating hydrometeors fall instantaneously to the ground. Therefore, the impact of hydrometeor drift on the QPF is not taken into account in these two coarseresolution systems. This can be problematic for forecasting precipitation distribution in mountainous terrain, where $C_{\mathrm{cw}}$ can sometimes be comparable to $C_{\mathrm{wv}}$ in Eq. (2).

On the other hand, the HRDPS- $2.5 \mathrm{~km}$ running at near cloud-resolving scale has a better representation of orography and other important sources of topographic forcing, as compared to the two coarser-resolution systems. For the predictions of the two winter storms in 2016 and 2017, the clouds and precipitation in the HRDPS- $2.5 \mathrm{~km}$ were computed using a combination of the Kuo transient shallow convection scheme and the double-moment version of the Milbrandt and Yau (2005a,b) bulk microphysics (MY2) scheme, which allows explicit prediction of moisture-hydrometeor conversion and hydrometeor movement in the atmosphere. Therefore, the hydrometeor drift effect is taken into account in the QPF field of the HRDPS. This represents a distinct benefit for precipitation prediction over complex terrain.

On 18 September 2018, the operational HRDPS$2.5 \mathrm{~km}$ was upgraded to a new cloud microphysics, the Predicted Particle Properties (P3) scheme, in which all ice-phase particles are represented by several physical properties that evolve freely in time and space (Morrison and Milbrandt 2015; Morrison et al. 2015; Milbrandt et al. 2016). The advantage of the P3 scheme over the MY2 scheme will be demonstrated in section 5 .

\section{The 26-28 January 2016 storm}

\section{a. Synoptic analysis}

As shown in Fig. 1, an intense winter frontal system moved across BC during 26-28 January 2016. Through this 3-day period, the synoptic conditions were characterized by an intense extratropical cyclone in the Northeast Pacific and an anticyclone centered over the Rocky Mountains, as represented by the mean sea surface pressure (MSLP) and 500-hPa geopotential height (Z500) patterns in Fig. 3. The cyclone initiated off the east coast of Japan on 23 January, and deepened rapidly as it traveled across the North Pacific Ocean. By 0000 UTC 27 January (1600 PST 26 January), the cyclone became vertically stacked from the surface through the 500-hPa level. Associated with this occluded cyclone was a long cold front trailing southwestward into the subtropical Northwest Pacific and a warm front heading toward northern BC. Twelve hours later at 1200 UTC (Figs. 3c,d), the warm front made landfall and the MSLP at the cyclonic center had risen from 950 to $955 \mathrm{hPa}$. By 0000 UTC 28 January (Fig. 3e), the cyclone had weakened further, with the minimum MSLP rising to $962 \mathrm{hPa}$. By this time, the cold front had made landfall on the $\mathrm{BC}$ Central Coast. It moved slowly across southern $\mathrm{BC}$ and reached Metro Vancouver around 1200 UTC (Fig. 3f).

Through this period, the robust presence of the high pressure system centered over the Rocky Mountains also had a major influence on the storm development. Its extension over the subtropical Northeast Pacific not only acted to slow down the passage of the front across $\mathrm{BC}$, but also helped to strengthen the pre-cold-frontal low-level jet (LLJ) and the associated AR. 
(a) MSLP, 0000 UTC 27 Jan

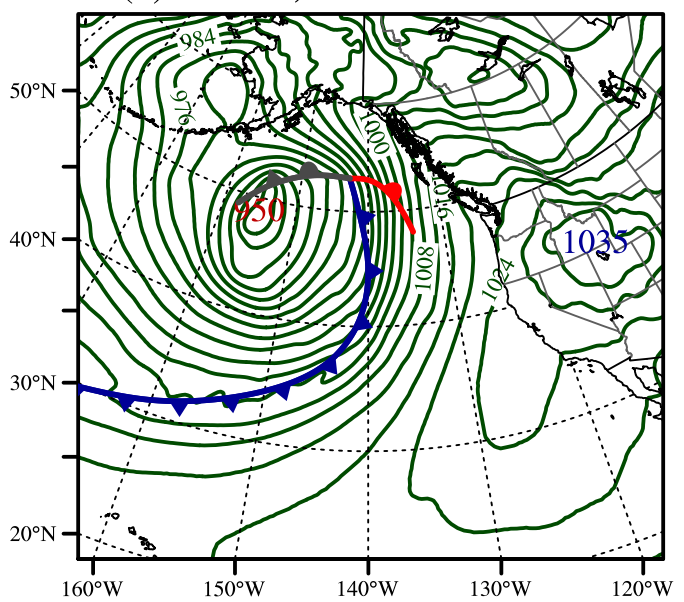

(c) MSLP, 1200 UTC 27 Jan

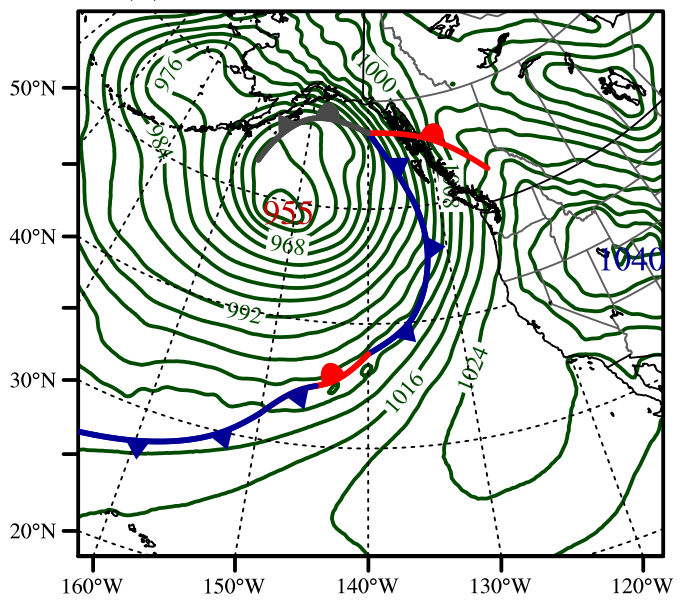

(e) MSLP, 0000 UTC 28 Jan

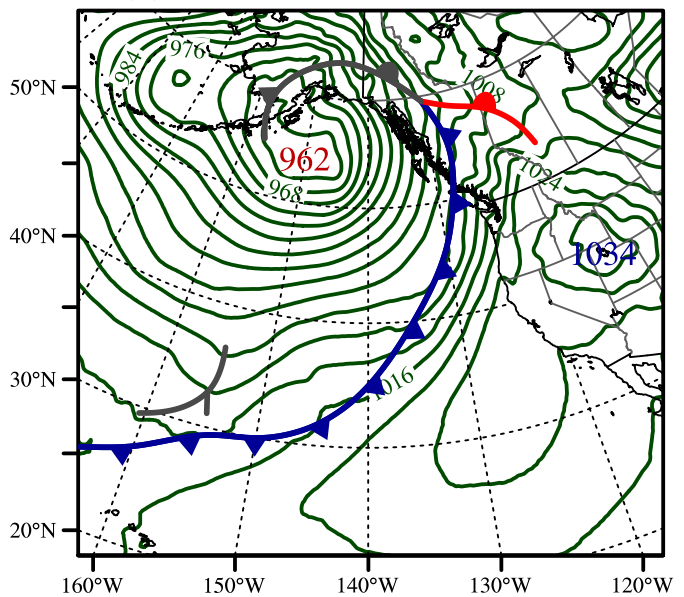

(b) Z500, 0000 UTC 27 Jan

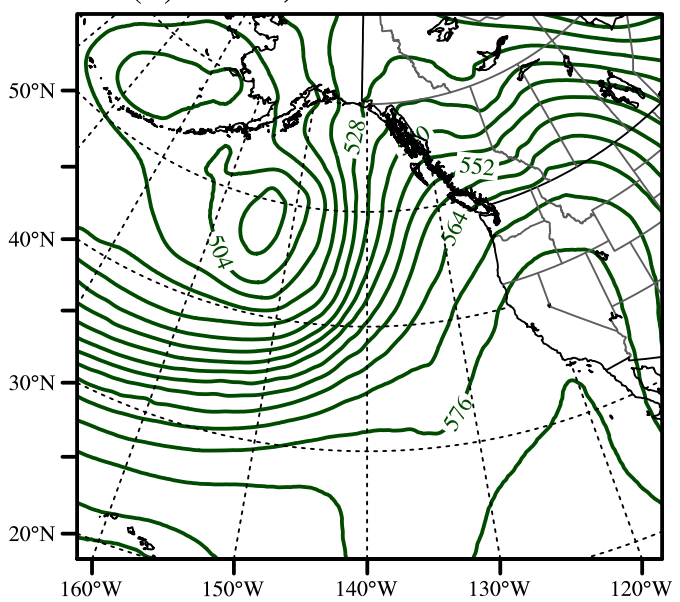

(d) Z500, 1200 UTC 27 Jan

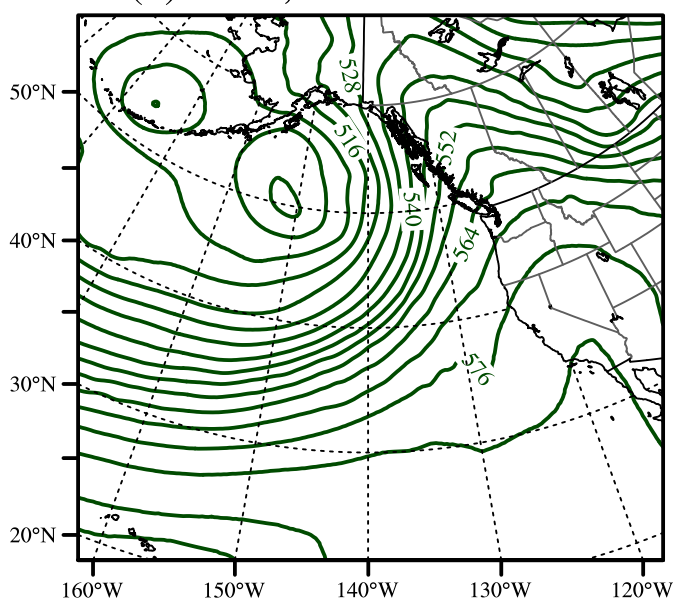

(f) MSLP, 1200 UTC 28 Jan

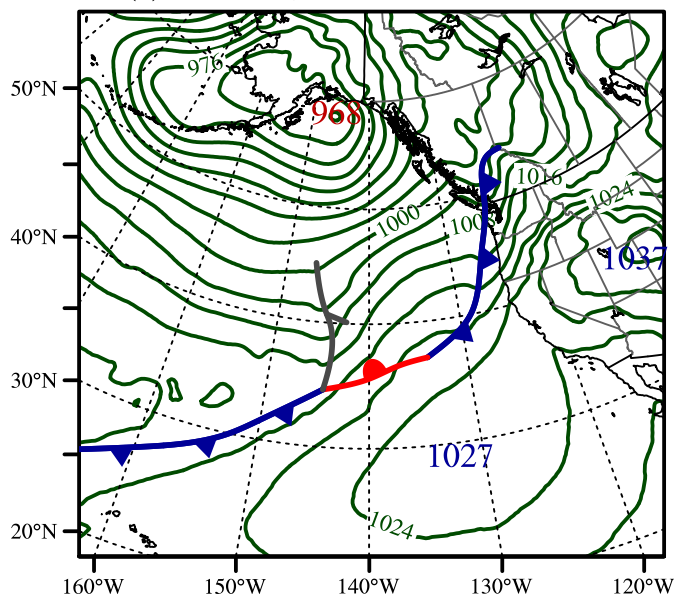

FIG. 3. (a), (c), (e), (f) MSLP (contour interval: 4 hPa) with frontal analysis and (b), (d) Z500 (contour interval: 6 dam) during 27-28 Jan 2016, based on the GDPS-25km analysis (0-h prediction). 
(a) 0000 UTC 27 Jan 2016

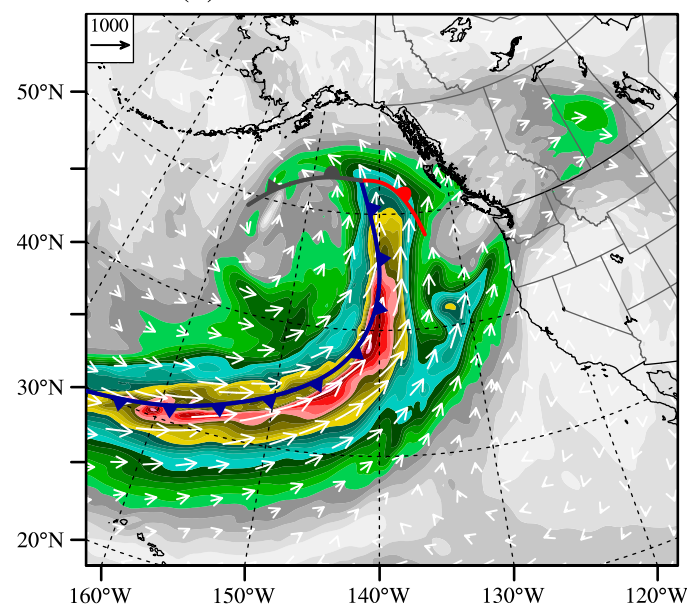

(c) 0000 UTC 28 Jan 2016

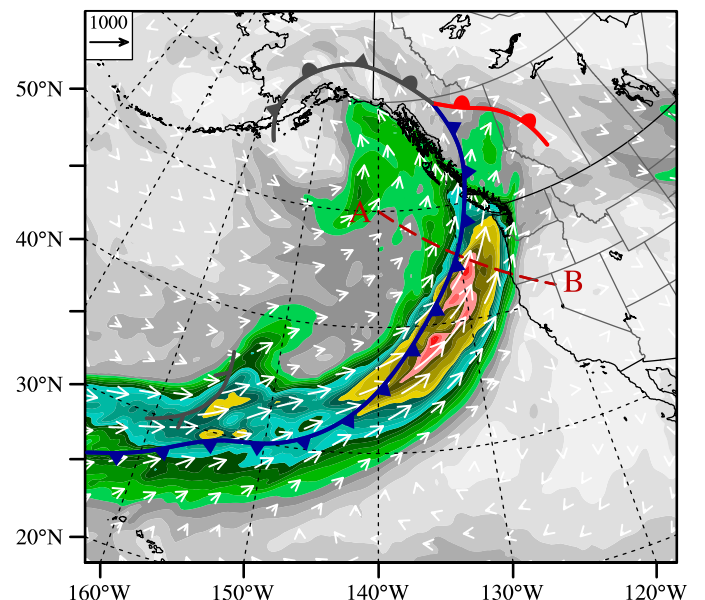

(b) 1200 UTC 27 Jan 2016

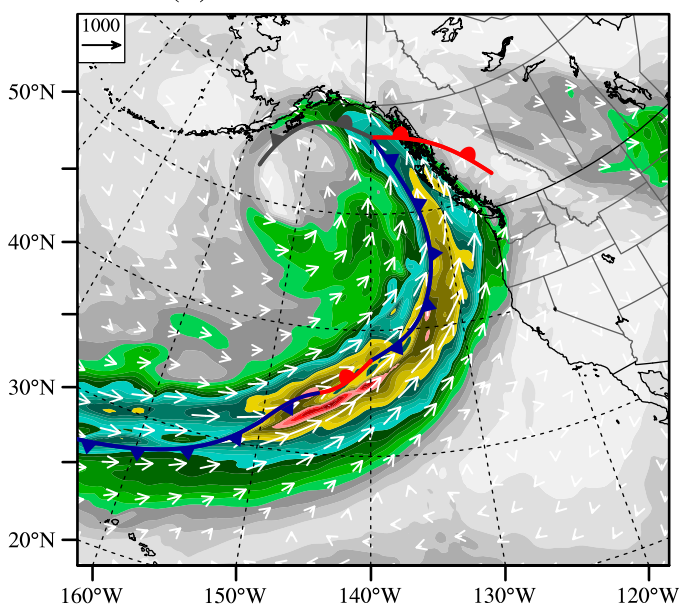

(d) 1200 UTC 28 Jan 2016

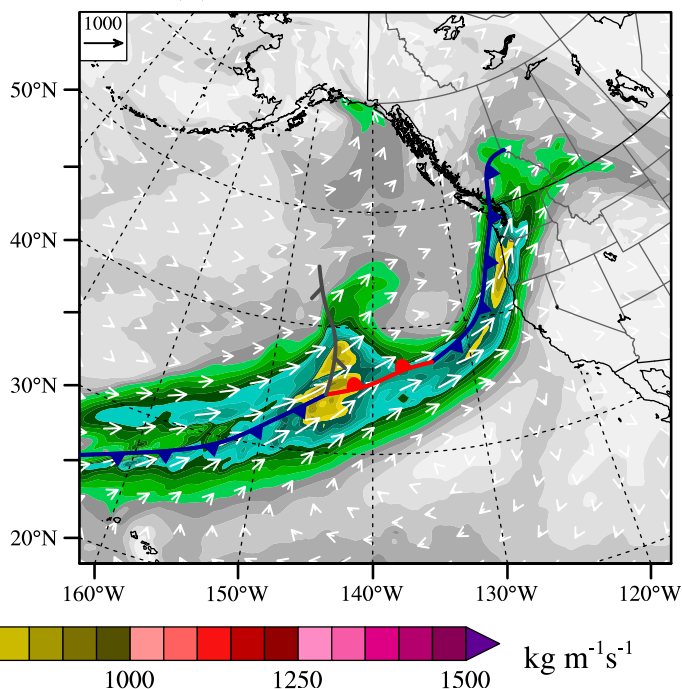

FIG. 4. Distributions of the vertically integrated water vapor flux vector $\mathbf{Q}$ and the corresponding IVT, $|\mathbf{Q}|$ (color shaded; $\mathrm{kg} \mathrm{m}^{-1} \mathrm{~s}^{-1}$ ) during 27-28 Jan 2016, based on the GDPS-25km analysis (0-h prediction). The vertical integration is from Earth's surface to the $100-\mathrm{hPa}$ level. The red dashed line from A to B in (c) is used to create the vertical cross-section charts in Fig. 5.

\section{b. Atmospheric river analysis}

Atmospheric rivers can be generally defined as long, narrow, and transient corridors of strong horizontal water vapor transport (American Meteorological Society 2019). For operational forecast applications on the west coast of Canada, a simple IVT-based AR definition is used: an elongated area with a minimum IVT threshold of $250 \mathrm{~kg} \mathrm{~m}^{-1} \mathrm{~s}^{-1}$, a minimum length of $1500 \mathrm{~km}$, and a length/width ratio > 2 (cf. Rutz et al. 2014; Wick 2014; Guan and Waliser 2015; Mahoney et al. 2016; Mo and Lin 2019).

Figure 4 shows four snapshots of the IWVF/IVT distributions during the January 2016 storm. At 0000 UTC
27 January, a strong AR can be identified ahead of the cold front (Fig. 4a). It brought warm, moist air to the coastal waters off Vancouver Island by 1200 UTC (Fig. 4b), and made landfall on the BC South Coast around 1800 UTC (not shown). It produced the heaviest rainfall on West Vancouver Island in the following six hours (Fig. 4c), and weakened markedly as it reached the Washington and Oregon coasts around 1200 UTC 28 January (Fig. 4d).

The vertical structure of the AR at 0000 UTC 28 January is shown in Fig. 5. The cross-section line is from A to B in Fig. 4c. The thick blue lines correspond to the $308-\mathrm{K}$ contour of the equivalent potential temperature (EPT); they were drawn to highlight the boundaries between the warm and cold air masses. 
(a) Wind speed (colors) and EPT (lines, K)

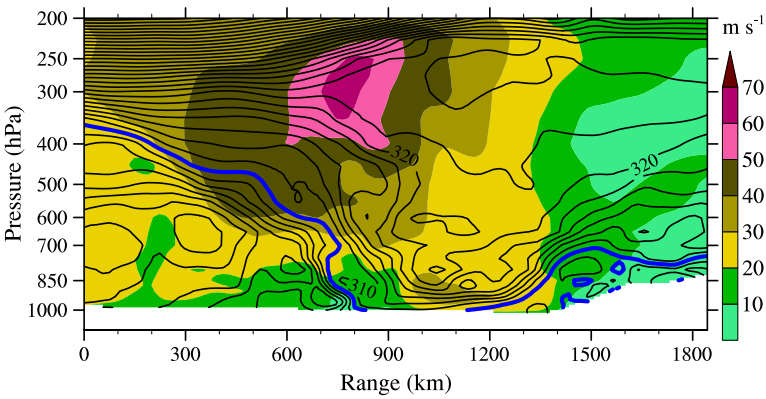

(b) WVF (colors) and specific humidity (lines, $\mathrm{g} \mathrm{kg}^{-1}$ )

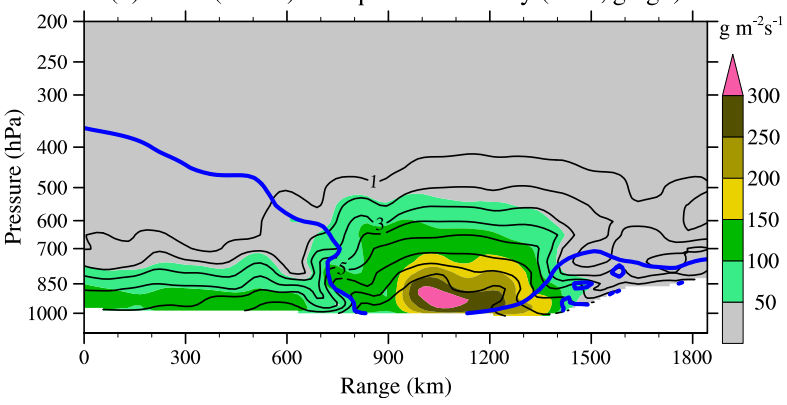

FIG. 5. Vertical cross sections along the red dashed line from A to $B$ in Fig. 4c, based on the GDPS-25km analysis valid at 0000 UTC 28 Jan 2016. (a) Wind speed (color shaded; $\mathrm{m} \mathrm{s}^{-1}$ ) and EPT (solid lines; contour interval: $2 \mathrm{~K}$ ). (b) WVF (color shaded; $\mathrm{g} \mathrm{m}^{-2} \mathrm{~s}^{-1}$ ) and specific humidity (solid lines; contour interval: $1 \mathrm{~g} \mathrm{~kg}^{-1}$ ). The thick blue lines represent the $308-\mathrm{K}$ contour of EPT in (a).

In Fig. 5a, the blue line on the left can be considered as the cold front below an upper-level jet, and there was an LLJ between the 850 and $950 \mathrm{hPa}$ levels at a distance about $250 \mathrm{~km}$ ahead of this cold front. In Fig. 5b, the area with the magnitude of water vapor flux (WVF) greater than $150 \mathrm{~g} \mathrm{~m}^{-2} \mathrm{~s}^{-1}$ can be considered as the AR core that was collocated with the LLJ seen in Fig. 5a. The width of this area is about $450 \mathrm{~km}$, which is close to the width of the AR bounded laterally by the positions of IVT $=500 \mathrm{~kg} \mathrm{~m}^{-1} \mathrm{~s}^{-1}$ in Fig. 4c.

Benton and Estoque (1954) noted that a substantial supply of water vapor is necessary for heavy precipitation, but that a large moisture flux is not a sufficient condition for heavy precipitation. As shown in Eq. (2), the precipitation rate is directly linked to the convergence rather than the strength of IWVF. Along the moist jet stream of an AR, significant hydrometeor drift is also expected, and its impact on the precipitation rate is measured by the convergence of ICWF.

Figure 6 shows the five components on the righthand side of Eq. (2) valid at 0000 UTC 28 January 2016 (cf. Moore and Holdsworth 2007). They were calculated from the GDPS- $25 \mathrm{~km}$ predictions initialized at 0000 UTC 27 January. Note that the archived model data are available only every hour, and they do not include the evaporation rate and tendencies of water content. Here we calculated $\partial W / \partial t$ and $\partial W_{c} / \partial t$ at 0000 UTC based on the predicted $W$ and $W_{c}$ for 2300 UTC ( $1 \mathrm{~h}$ before) and $0100 \mathrm{UTC}(1 \mathrm{~h}$ after). The evaporation rate in Fig. 6e was estimated from the nearsurface upward latent heat flux $F_{\mathrm{LH}}^{s}$ (i.e., $E=F_{\mathrm{LH}}^{s} / L_{v}$, where $L_{v}=2.501 \times 10^{6} \mathrm{~J} \mathrm{~kg}^{-1}$ is the latent heat of vaporization) (cf. Cordeira et al. 2013).

In Fig. 6a, the highest horizontal moisture convergences (i.e., areas with $C_{\mathrm{wv}}>4 \mathrm{~mm} \mathrm{~h}^{-1}$ ) occurred on the windward slopes of the coastal mountain ranges. Here, the landfalling AR not only brought in a large amount of moisture from remote sources, but also forced the moist air to converge and rise. The rain-shadow effect is reflected by the local minimum values of $C_{\mathrm{wv}}$ on the leeward slopes. Modest moisture convergences also occurred on the windward slopes of the Columbia Mountains and ahead of the warm front in Central Alberta.

The impact of hydrometeor drift on the precipitation rate is represented by the horizontal convergence of condensed water $\left(C_{\mathrm{cw}}\right)$ in Fig. $6 \mathrm{~b}$. It appears that this component is about 3-20 times smaller than $C_{\mathrm{wv}}$ in Fig. 6a in most areas. There were four significant dipole patterns with $C_{\mathrm{cw}}<0$ in the southwest and $C_{\mathrm{cw}}>0$ in the northeast across the Vancouver Island Ranges, the Olympic Mountains, and the Coast-Cascade Mountains, indicating that a portion of the hydrometeors forming over the windward side was driven by the strong winds toward the crest or leeward slope. The center of large positive $C_{\mathrm{cw}}$ over East Vancouver Island is a robust indication for spillover of precipitation. The impact of hydrometeor drift is also evident over and across the Coast-Cascade Mountains, where $C_{\mathrm{wv}}$ in Fig. 6a has a small or negative value.

The IWV tendency distribution in Fig. $6 \mathrm{c}$ can be better understood by comparing it with the $C_{\mathrm{wv}}$ distribution in Fig. 6a. In some areas, such as Central Alberta, the values of $\partial W / \partial t$ are positive and as large as the positive values of $C_{\mathrm{wv}}$. Their contributions to the precipitation rate would cancel each other in Eq. (2). These were the dry areas, where the initial moisture convergences led to the rapid increase of precipitable water rather than immediate precipitation. Heavy precipitation was expected in the coastal areas where the air had been highly saturated, so that the converged moisture would condense and fall as precipitation.

The contributions of the ICW tendency (Fig. 6d) and the surface evaporation rate (Fig. 6e) were relatively small and negligible in most areas. Note that the ICW tendency is much smaller than the IWV tendency in Fig. 6, and it is even smaller than the evaporation in most areas. The "precipitation rate" given by the sum of these five diagnosed components is shown in Fig. $6 f$. 
(a) $C_{w v}=-\nabla \cdot \mathbf{Q}$

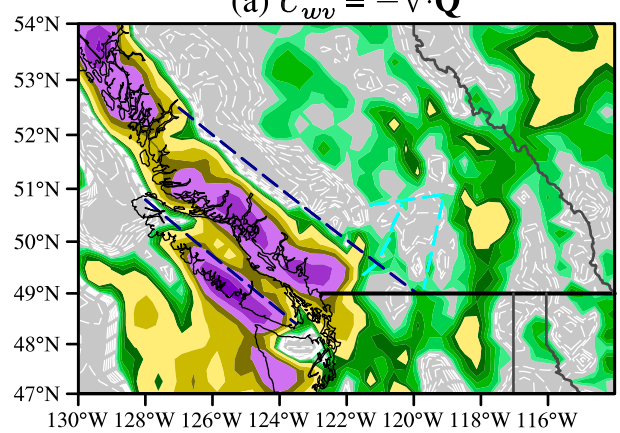

(c) $\partial W / \partial t$

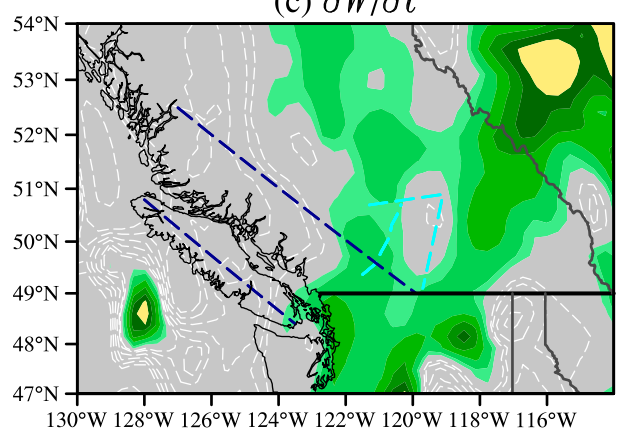

(e) $E$

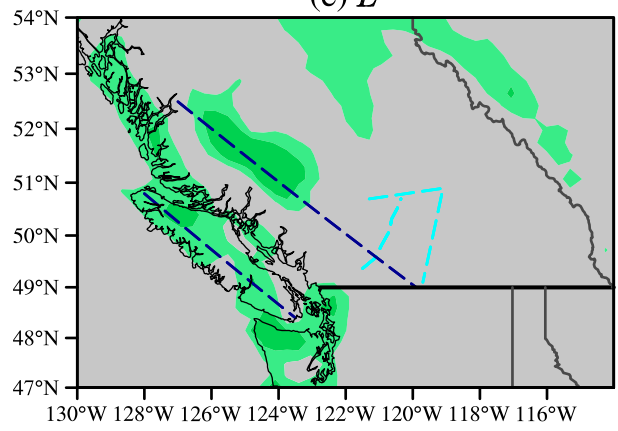

(b) $C_{c w}=-\nabla \cdot \mathbf{Q}_{c}$

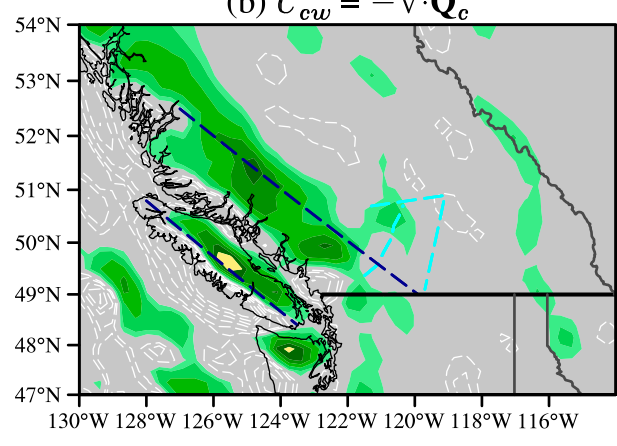

(d) $\partial W_{c} / \partial t$

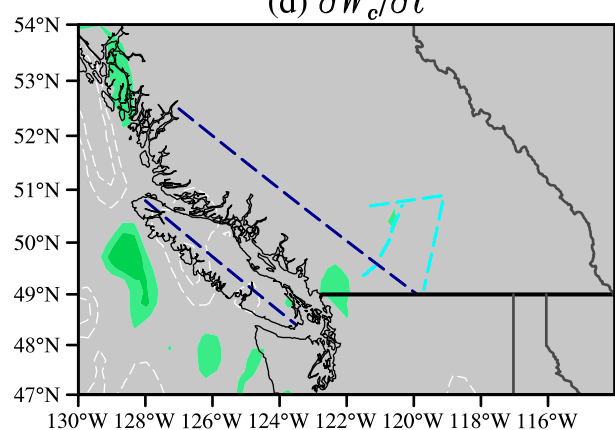

(f) $P=E-\partial\left(W+W_{c}\right) / \partial t-\nabla \cdot\left(\mathbf{Q}+\mathbf{Q}_{c}\right)$

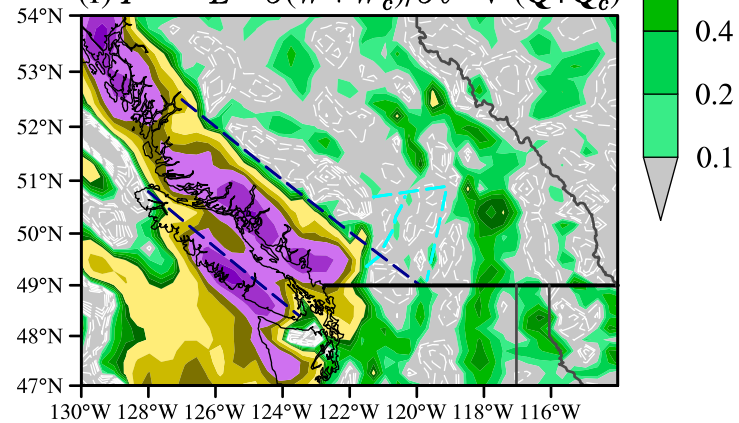

$\mathrm{mm} \mathrm{h}^{-1}$

FIG. 6. The five components from the decomposition of precipitation rate in Eq. (2), valid at 0000 UTC 28 Jan 2016, based on the GDPS-25km 24-h prediction initialized at 0000 UTC $27 \mathrm{Jan}$. Positive values are color coded, and negative values are contoured by white dashed lines for $-0.1,-0.2, \ldots,-20.0 \mathrm{~mm} \mathrm{~h}^{-1}$ (i.e., negative values on the color bar). (a) Convergence of IWVF. (b) Convergence of ICWF. (c) Tendency of IWV. (d) Tendency of ICW. (e) Evaporation rate. (f) The sum of the five components.

It should be pointed out that the true precipitation rate is a nonnegative quantity $(P \geq 0)$. Therefore, the negative values in Fig. $6 f$ are not physically meaningful and must be attributed to the systematic errors with the diagnostic process (Trenberth and Guillemot 1998; Moore and Holdsworth 2007). If all negative values in Fig. 6f are converted to zero, we are able to recognize a typical AR-enhanced orographic precipitation distribution in southern BC, with heavy precipitation due to orographic enhancement on the windward slopes of the coastal mountain ranges and a possible spillover event in East Vancouver Island. On the other hand, the relatively large positive values of $C_{\mathrm{cw}}$ on the leeward side of the Coast-Cascade Mountains in Fig. 6b were completely overwhelmed by the systematic errors $(P<0)$ in Fig. 6 f.

A closer examination of the systematic errors (negative values) in Fig. 6f reveals that most of them are associated with the strong moisture divergences $\left(C_{\mathrm{wv}}<0\right)$ in Fig. 6a. In reality, the loss of moisture in an air column through horizontal divergence should be balanced by the decrease of precipitable water $(\partial W / \partial t<0)$ and the local moisture supply from surface evaporation $(E>0)$ or hydrometeor evaporation/sublimation $\left(\partial W_{c} / \partial t<0\right)$. However, since $\partial\left(W+W_{c}\right) / \partial t$ was diagnosed from archived model data at two time points separated by two hours, one cannot expect that water vapor is always conserved in the diagnostic analysis. We shall come back to this issue later in this section. 


\section{c. Observed rainfall distribution and weather warnings}

The routine weather forecasts and warnings for BC are issued by the Pacific Storm Prediction Centre in Vancouver. The 24-h rainfall warning criteria for the outer coastal areas (including Inland Vancouver Island) is $100 \mathrm{~mm}$, whereas it is $50 \mathrm{~mm}$ elsewhere in the province. Public warnings are typically only issued for communities, transportation routes, and for the lowest $300-400 \mathrm{~m}$ of valleys where most people live, travel, and work. Therefore, warnings will normally not be issued when criteria are only expected to be exceeded over high elevations in mountainous terrain.

The orographic precipitation associated with this winter storm is analyzed using observed data from 171 rain gauges across southern $\mathrm{BC}$. Figure $7 \mathrm{a}$ plots the time series of hourly precipitation amounts at five selected stations for the 2-day period starting at 0000 UTC 27 January 2016. These stations are marked in black color on Fig. 2b. The precipitation amounts at all 171 stations for the 24-h period ending at 1800 UTC on the 28th are plotted in Figs. 7b and 8. It is shown that heavy rain began to develop soon after 0600 UTC 27 January over West Vancouver Island. All four stations in this region reported 24-h rainfall amounts exceeding $170 \mathrm{~mm}$ (Figs. 7b and 8a). The heaviest rain was observed at a forestry station named Effingham (FEH; $49.17^{\circ} \mathrm{N}$, $125.28^{\circ} \mathrm{W}$ ), with a two-day total amount of $583 \mathrm{~mm}$ and a maximum hourly amount of $41 \mathrm{~mm}$ at 2000 UTC. In Fig. 8a, the 24-h precipitation amount at FEH is $379 \mathrm{~mm}$, much higher than the $180 \mathrm{~mm}$ at a nearby station [Kennedy Lake $(\mathrm{HKN}) ; 49.10^{\circ} \mathrm{N}, 125.45^{\circ} \mathrm{W}$ ]. It is known to operational meteorologists at the Pacific Storm Prediction Centre that this station usually reports much heavier precipitation than surrounding stations under such circumstances, and the BC Wildfire Service confirmed that the rain gauge at this station was in good condition during this storm (E. Meyer 2016, personal communication). As shown in Fig. 8a, this station is located on a mountain slope where heavy rainfall could be triggered by moist flow channeling through multiple valleys (as illustrated by three red arrows).

Figure 8 a shows that heavy rain also spread to some rain-shadow areas in East Vancouver Island, such as the 24-h totals of $121 \mathrm{~mm}$ at Bowser $\left(\mathrm{FBO} ; 49.44^{\circ} \mathrm{N}\right.$, $124.70^{\circ} \mathrm{W}$ ) and $103 \mathrm{~mm}$ at Cochrane (HRN; $49.37^{\circ} \mathrm{N}$, $\left.124.60^{\circ} \mathrm{W}\right)$. These high amounts were underforecast and East Vancouver Island was not included in the initial rainfall warning bulletin for this storm.

Heavy rain spread to the Lower Mainland area after 1800 UTC 27 January (Figs. 7b and 8b). The heaviest rain fell in Howe Sound due to the orographic channeling effect. The storm total amount at Port Mellon (VOM; $49.53^{\circ} \mathrm{N}, 123.50^{\circ} \mathrm{W}$ ) was $218 \mathrm{~mm}$ (Fig. $7 \mathrm{a}$ ). In comparison, the Vancouver Sea Island station (VVR; $49.18^{\circ} \mathrm{N}, 123.19^{\circ} \mathrm{W}$, near the Vancouver International Airport) only reported a total amount of $32 \mathrm{~mm}$. Near the North Shore Mountains, the 24-h rainfall amounts were above $50 \mathrm{~mm}$. In and beyond the Lower Fraser Valley, the channeling effect also resulted in rainfall amounts exceeding the warning criterion of $50 \mathrm{~mm} \mathrm{day}^{-1}$ at several stations (Fig. 8b).

Figure $7 \mathrm{~b}$ shows that moderate precipitation amounts were observed at two stations located at the lee side of the Coast-Cascade Mountains: $48 \mathrm{~mm}$ at Talchako $\left(\mathrm{FTO}, 52.25^{\circ} \mathrm{N}, 126.03^{\circ} \mathrm{W}\right.$ ) and $41 \mathrm{~mm}$ at Tatlayoko Lake (XTL; $\left.51.67^{\circ} \mathrm{N}, 124.40^{\circ} \mathrm{W}\right)$. These near-warning amounts likely resulted from the combined effect of spillover and local orographic enhancement. There were also a few stations in the northern Columbia and Rocky Mountains with $30-40 \mathrm{~mm}$. The time series for the McGregor station (FRG; $53.93^{\circ} \mathrm{N}, 120.64^{\circ} \mathrm{W}$ ) in Fig. 7a shows a storm total precipitation amount of $45 \mathrm{~mm}$. The actual amount could be higher or lower, given that this forestry station with a tipping-bucket gauge was located at an elevation of $975 \mathrm{~m}$ above sea level, and the station temperature rose to above $0^{\circ} \mathrm{C}$ only after $1800 \mathrm{UTC}$ 27 January. The heavy precipitation and snow level changes in this area were partially responsible for the massive avalanche on the 29th that killed five snowmobilers (Lindsay 2016).

For this winter storm, the first rainfall warning was issued by operational meteorologists at the Pacific Storm Prediction Centre for Metro Vancouver, Howe Sound, and Sunshine Coast at 1245 UTC 27 January. This warning was verified as a hit for these regions with a short lead time of $6-12 \mathrm{~h}$. East Vancouver Island was added to the warning list at 2310 UTC. This was verified as a late warning triggered by observations. Ironically, rainfall warnings for West and Inland Vancouver Island came out even later at 2352 UTC. Although the warning criterion for these two regions is higher at $100 \mathrm{~mm} \mathrm{day}^{-1}$, the late warning was related to the fact that the precipitation potential of this AR system was seriously underestimated. No warning was issued for the Lower Fraser Valley, where several stations reported more than $50 \mathrm{~mm}$ within $24 \mathrm{~h}$ (Fig. $7 \mathrm{~b}$ ). Inconsistencies in the model QPF amounts certainly had an impact on the decision process for issuing warnings for these regions.

\section{d. Precipitation rates mapping with observations}

The observed and model predicted precipitation rates valid at 0000 UTC 28 January 2016 are plotted in Fig. 9. As mentioned in section 3, the forecast 


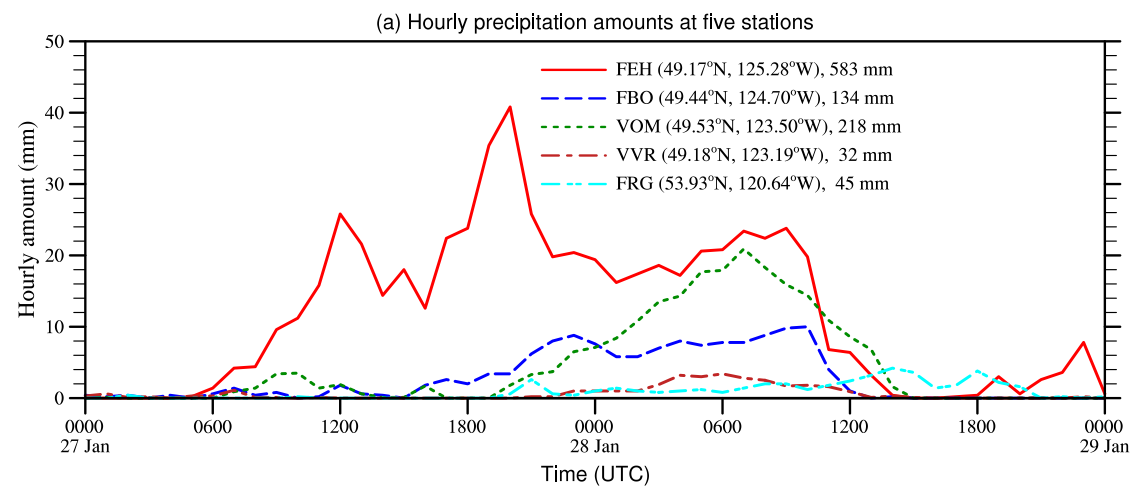

(b) 24-h precipitation amounts (1800--1800 UTC)

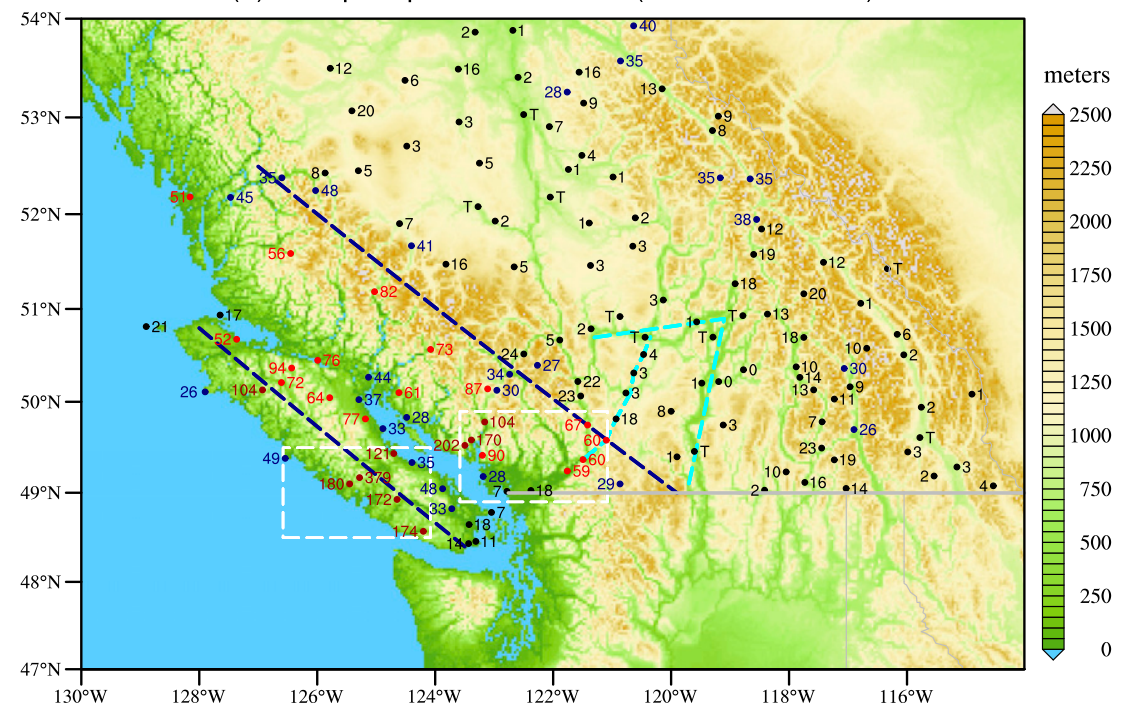

FIG. 7. (a) Time series of hourly precipitation amounts observed at five weather stations: Effingham (FEH), Bowser (FBO), Port Mellon (VOM), Vancouver Sea Island (VVR), and McGregor (FRG). The locations of these stations are marked by black dots in Fig. 2b. The storm-total (48-h) precipitation amount at each station is indicated in the legend. (b) Colorcoded precipitation amounts $(\mathrm{mm})$ observed over the 24 -h period ending at 1800 UTC 28 Jan 2016. Amounts $\leq 25 \mathrm{~mm}$ are plotted in black (with " $T$ " standing for trace amount $<0.2 \mathrm{~mm}$ ), $25-50 \mathrm{~mm}$ in blue, $50-100 \mathrm{~mm}$ in red, and $\geq 100 \mathrm{~mm}$ in dark red. The two squared areas marked by white dashed lines are plotted in Fig. 8.

precipitation rate (FPR) of the HRDPS-2.5km in Fig. 9a was given by the MY2 microphysics scheme that allows explicit prediction of hydrometeor drift. The GDPS-25km FPR in Fig. 9b was from a diagnostic scheme that advects only nonsedimenting condensate and ignores the drift of precipitating hydrometeors. The RDPS-10km FPR distribution is similar to its GDPS-25km counterpart, and therefore is not shown in Fig. 9. For the purpose of demonstration, two additional precipitation rates derived from the GDPS $-25 \mathrm{~km}$ output, based on an atmospheric water balance (AWB) scheme and a hydrometeor drift calibration (HDC) scheme, are shown in Fig. 9c and Fig. 9d, respectively. They are defined as follows, with negative values being converted to zero:

$$
\begin{gathered}
P_{\mathrm{AWB}}=\left(\mathrm{ECR}-\nabla \cdot \mathbf{Q}_{c}\right) \geq 0, \\
P_{\mathrm{HDC}}=\left(\mathrm{FPR}-\nabla \cdot \mathbf{Q}_{c}\right) \geq 0,
\end{gathered}
$$

where ECR stands for "equivalent condensation rate," defined as a nonnegative parameter as

$$
\mathrm{ECR}=\left[E-\partial\left(W+W_{c}\right) / \partial t-\nabla \cdot \mathbf{Q}\right] \geq 0 .
$$

A further explanation of these definitions will be given later. For now let us first focus on the evidence of hydrometeor drift and spillover of precipitation that can be readily identified by comparing Fig. 9a with Fig. 9b. As pointed out in the previous section, the precipitation scheme of the GDPS- $25 \mathrm{~km}$ does not take into account 
(a) Central Vancouver Island

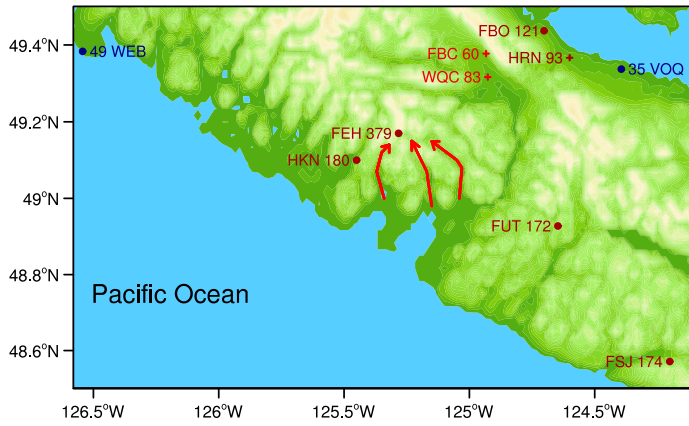

(b) Lower Mainland \& Howe Sound

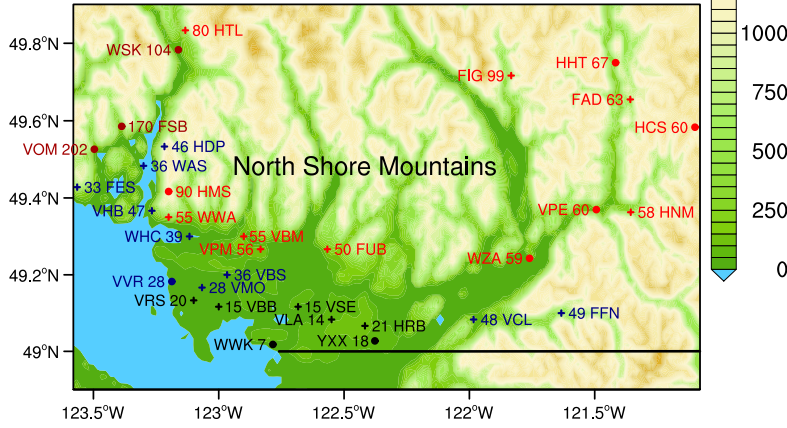

FIG. 8. Color-coded precipitation amounts $(\mathrm{mm})$ observed over the 24-h period ending at 1800 UTC 28 Jan 2016 in two subdomains marked by white lines in Fig. 7b: (a) Central Vancouver Island and (b) Lower Mainland and Howe Sound. Amounts $\leq 25 \mathrm{~mm}$ are plotted in black, $25-50 \mathrm{~mm}$ in blue, $50-100 \mathrm{~mm}$ in red, and $\geq 100 \mathrm{~mm}$ in dark red. Stations that cannot be fitted into Fig. $7 \mathrm{~b}$ are marked by a plus symbol.

the hydrometeor drift effect. Therefore, some differences between Fig. 9a and Fig. 9b can be attributed to the impact of hydrometeor drift. It is shown that the major difference is a clear downwind shift of the HRDPS-2.5km FPR pattern as compared to its GDPS$25 \mathrm{~km}$ counterpart in Fig. 9a. The hydrometeor drift and spillover are particularly evident in the lee of the Coast-Cascade Mountains (i.e., east of the blue dashed line). A precipitation rate of $3.6 \mathrm{~mm} \mathrm{~h}^{-1} \mathrm{ob}$ served at the Tatlayoko Lake station (XTL; $51.67^{\circ} \mathrm{N}$, $124.40^{\circ} \mathrm{W}$ ) is marked by a small red circle. At this location, the predicted rates of the HRDPS-2.5km (Fig. 9a) and the GDPS-25km FPR (Fig. 9b) are 2.5 and $0.0 \mathrm{~mm} \mathrm{~h}^{-1}$, respectively.

The local terrain feature and hydrometeor drift also have a remarkable impact on the precipitation distribution in the vicinity of Metro Vancouver (upwind side of the North Shore Mountains, marked by the large red circle in Fig. 9). In this region, the highest precipitation rates predicted by the HRDPS- $2.5 \mathrm{~km}$ (with much better terrain resolution) are close to the mountains, in contrast to some high rates in the lowlands predicted by the GDPS-25km (with coarser terrain resolution).
Located in the center of the red circle is a special ECCC autostation called "VVR" near the Vancouver International Airport, which reported a precipitation rate of $1.0 \mathrm{~mm} \mathrm{~h}^{-1}$. The predicted rates by the HRDPS$2.5 \mathrm{~km}$ and the GDPS- $25 \mathrm{~km}$ are 1.1 and $5.2 \mathrm{~mm} \mathrm{~h}^{-1}$, respectively.

Since the diagnostic precipitation scheme of the GDPS-25km does not take into account the hydrometeor drift effect, its FPR in Fig. 9b is equivalent (or very similar) to the ECR defined by Eq. (6). Therefore, it should not be surprising that the precipitation rate distribution of the AWB scheme in Fig. 9c bears a close resemblance to the FPR distribution in Fig. 9b. In particular, on the windward slopes of the Vancouver Island Ranges and the Coast-Cascade Mountains, the maximum values of $P_{\mathrm{AwB}}$ and FPR were in the range of $6-10 \mathrm{~mm} \mathrm{~h}^{-1}$, consistent with most observations in this region (except for the much higher value of $17.8 \mathrm{~mm}$ observed at FEH). Since $P_{\mathrm{AWB}}$ in Eq. (4) also includes the convergence of condensed water $\left(-\nabla \cdot \mathbf{Q}_{c}\right)$, the impact of hydrometeor drift is also evident in Fig. 9c as compared to Fig. 9b, especially on the leeward slopes of the Coast-Cascade Mountains. Note that, at Tatlayoko Lake station (XTL), $P_{\mathrm{AwB}}$ has a positive value of $0.2 \mathrm{~mm} \mathrm{~h}^{-1}$, which is much smaller than the observed value of $3.6 \mathrm{~mm} \mathrm{~h}^{-1}$, but better than zero in the GDPS$25 \mathrm{~km}$ FPR. At the Vancouver International Airport (VVR) where the observed rate is $1 \mathrm{~mm} \mathrm{~h}^{-1}, P_{\mathrm{AWB}}=6.2 \mathrm{~mm} \mathrm{~h}^{-1}$, which is worse than $5.2 \mathrm{~mm} \mathrm{~h}^{-1}$ in the FPR. In theory, if each of the four components in the right-hand side of Eq. (6) and $\nabla \cdot \mathbf{Q}_{c}$ in Eq. (4) can be accurately diagnosed, then $P_{\mathrm{AWB}}$ should be close to the true precipitation rate. In practice, systematic errors may be caused by inadequate data and/or inappropriate diagnostic methods (Trenberth and Guillemot 1998; Moore and Holdsworth 2007). Our diagnosis used hourly data to calculate the tendency terms in Eq. (6), which introduced some large errors as manifested by the negative values in Fig. 6f. Although these explicit errors had been converted to zero in Fig. 9c, they were by no means corrected or negligible. There were also hidden (implicit) errors associated with the positive $P_{\mathrm{AwB}}$.

The $P_{\mathrm{HDC}}$ defined by Eq. (5) may be a more practically useful precipitation scheme. Instead of calculating the ECR from the model output using Eq. (6), it applies a hydrometeor drift calibration directly to the model FPR. Therefore, the systematic errors in this scheme should be much smaller than those in the AWB scheme. Note that, at XTL (small red circle, observed rate: $3.6 \mathrm{~mm} \mathrm{~h}^{-1}$ ), both $P_{\mathrm{HDC}}$ and $P_{\mathrm{AWB}}$ give a rate of $0.2 \mathrm{~mm} \mathrm{~h}^{-1}$, and FPR is zero. At VVR (large red circle, observed rate: $1.0 \mathrm{~mm} \mathrm{~h}^{-1}$ ), the values of $P_{\mathrm{HDC}}, P_{\mathrm{AWB}}$, and FPR are 4.6, 6.2, and $5.2 \mathrm{~mm} \mathrm{~h}^{-1}$, respectively. 
(a) HRDPS-2.5km forecast prediction rate

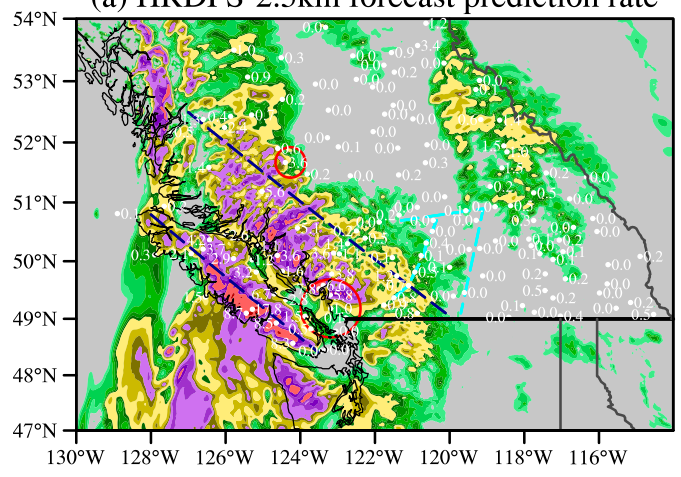

(c) GDPS-25km AWB precipitation rate

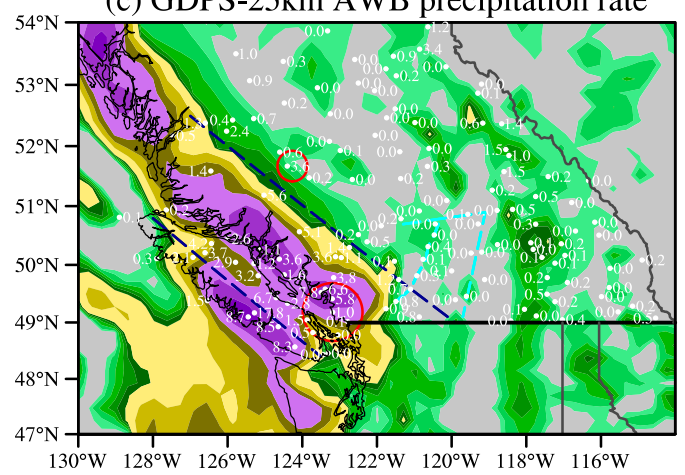

(b) GDPS-25km forecast precipitation rate

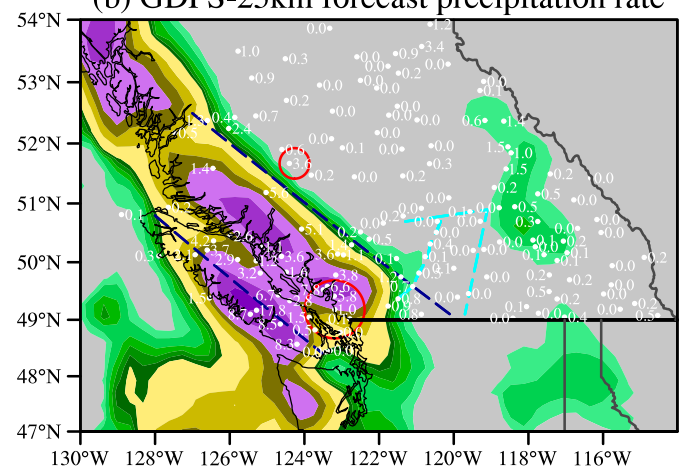

(d) GDPS-25km HDC prediction rate

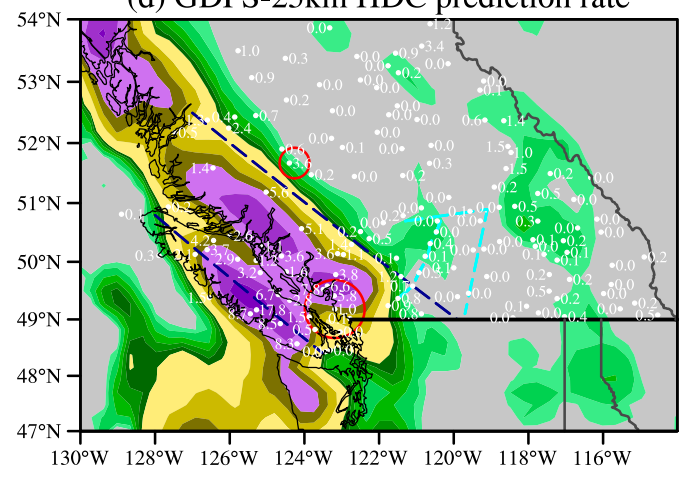

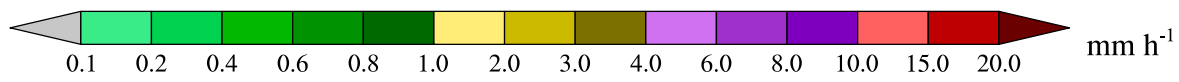

FIG. 9. Predicted (color-coded) and observed (white numbers) precipitation rates $\left(\mathrm{mm} \mathrm{h}^{-1}\right)$ valid at 0000 UTC 28 Jan 2016. The observed rates at 137 stations are based on the averages of two hourly precipitation amounts valid at 0000 and 0100 UTC. The predicted rates are based on the NWP systems initialized at 0000 UTC 27 Jan. (a) The forecast precipitation rate from the HRDPS- $2.5 \mathrm{~km}$ MY2 microphysics scheme. (b) The forecast precipitation rate from the GDPS-25km parameterization scheme. (c) The GDPS-25km AWB precipitation rate as defined in Eq. (4). (d) The GDPS-25km HDC precipitation rate as defined in Eq. (5). The small red circle highlights a precipitation rate of $3.6 \mathrm{~mm} \mathrm{~h}^{-1}$ observed at a station in the lee of the Coast-Cascade Mountains. The large red circle marks an area in the vicinity of Metro Vancouver.

\section{e. 24-h QPF patterns mapping with observations}

The precipitation amounts observed at the weather stations and predicted by the three NWP systems for the 24-h period ending at 1800 UTC 28 January 2016 are shown in Figs. 10 and 11. Some significant differences between the HRDPS- $2.5 \mathrm{~km}$ pattern and the GDPS$25 \mathrm{~km} / \mathrm{RDPS}-10 \mathrm{~km}$ patterns are due to the hydrometeor drift effects. Note that the $41 \mathrm{~mm}$ observed at the Tatlayoko Lake station in the lee of the Coast-Cascade Mountains was well predicted by the HRDPS- $2.5 \mathrm{~km}$, and the same for the $48 \mathrm{~mm}$ observed at a nearby forest station (FTO; $52.25^{\circ} \mathrm{N}$, $\left.126.03^{\circ} \mathrm{W}\right)$. The other two models underforecast the amounts at these two leeside stations.

In the Metro Vancouver area, the HRDPS-2.5km predicted amounts greater than $50 \mathrm{~mm}$ mainly near or over the North Shore Mountains (Fig. 11b), in contrast to the predictions of the other two coarser-resolution models.
At the airport, the Vancouver Sea Island station (VVR) observed an amount of $28 \mathrm{~mm}$ for this 24-h period. The predicted amounts for VVR by the HRDPS- $2.5 \mathrm{~km}$, RDPS- $10 \mathrm{~km}$, and GDPS-25km were about 25,50 , and $80 \mathrm{~mm}$, respectively. In Fig. 11b, the two violet lines represent the $50 \mathrm{~mm}$ contours predicted by the HRDPS$2.5 \mathrm{~km}$ (dashed) and the RDPS-10km (solid) in the Lower Mainland area. The HRDPS-2.5km predictions are much closer to the observations than the other two models.

To test the potential applications of the AWB and HDC schemes defined by Eqs. (4) and (5), we calculated $P_{\mathrm{AWB}}$ and $P_{\mathrm{HDC}}$ at each hour using the GDPS-25km hourly predictions initialized at 0000 UTC 27 January 2016 , and then integrated the two equations for $24 \mathrm{~h}$. The resulting QPFs are shown in Fig. 12. As compared with the original GDPS-25km QPFs in Fig. 10a, the AWB predictions in Fig. 12a achieve very slight improvements on the leeward slopes of the Coast-Cascade Mountains. 
(a) GDPS-25km predictions vs observations

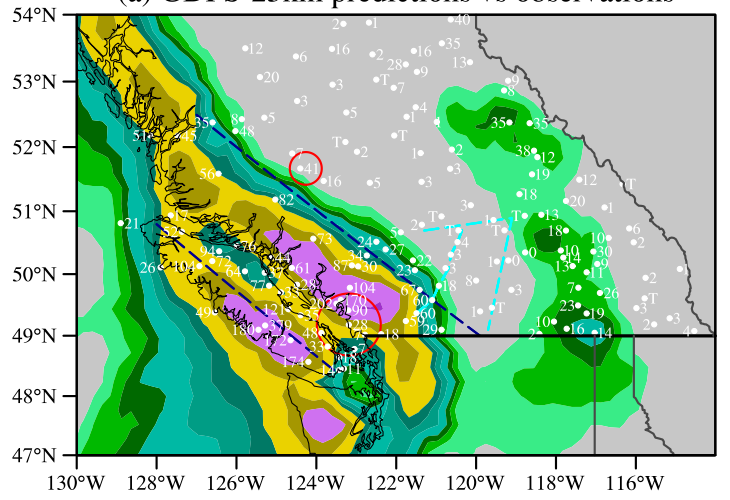

(b) RDPS-10km predictions vs observations

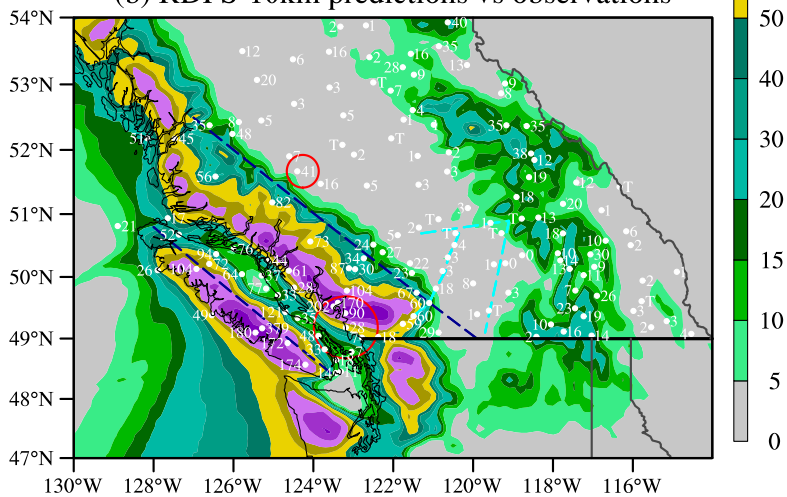

FIG. 10. Predicted (color shaded) and observed (white numbers) precipitation amounts $(\mathrm{mm})$ for the 24-h period ending at 1800 UTC 28 Jan 2016. (a) The GDPS-25km run and (b) the RDPS-10km run, both initialized at 0000 UTC 27 Jan. The small red circle highlights an amount of $41 \mathrm{~mm}$ observed at a station in the lee of the Coast-Cascade Mountains. The large red circle marks an area in the vicinity of Metro Vancouver.

Some AWB QPFs over the Columbia Mountains and the Rockies may also be better than the original QPFs. On coastal BC, the QPFs in Fig. 12a are slightly less accurate than those in Fig. 10a. The HDC QPFs plotted in Fig. $12 \mathrm{~b}$ are more accurate than the AWB QPFs in Fig. 12a and the original QPFs in Fig. 10a. It should be borne in mind that both the AWB and HDC QPFs were diagnosed and integrated based on the hourly model output. If the time intervals were shortened to 5 or $10 \mathrm{~min}$, these predictions would likely be more accurate than those shown in Fig. 12. Therefore, they have the potential to be implemented in real time with the model runs to improve the GDPS-25km and RDPS-10km QPFs.

\section{f. Objective $Q P F$ verifications}

The above analysis may be considered a subjective validation of the model QPFs for the AR-enhanced winter storm in BC on 26-28 January 2016. Figure 13 plots the model QPFs versus the observed 24-h precipitation amounts for this storm, and provides some (a) HRDPS- $2.5 \mathrm{~km}$ predictions vs observations

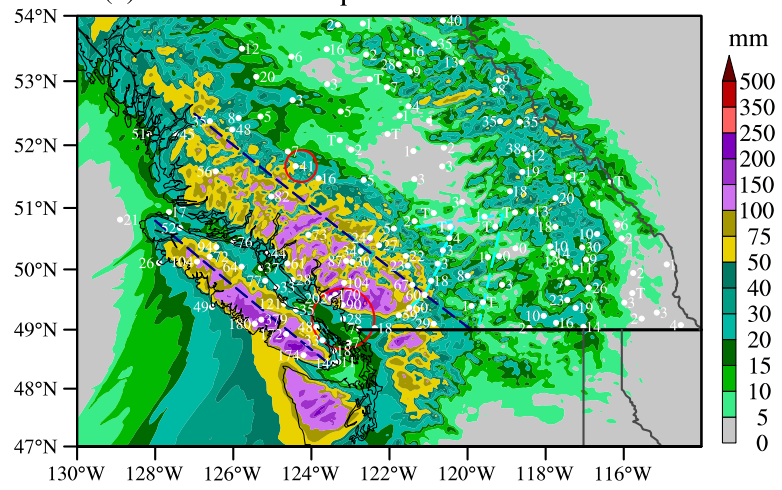

(b) Observations in Lower Mainland \& Howe Sound

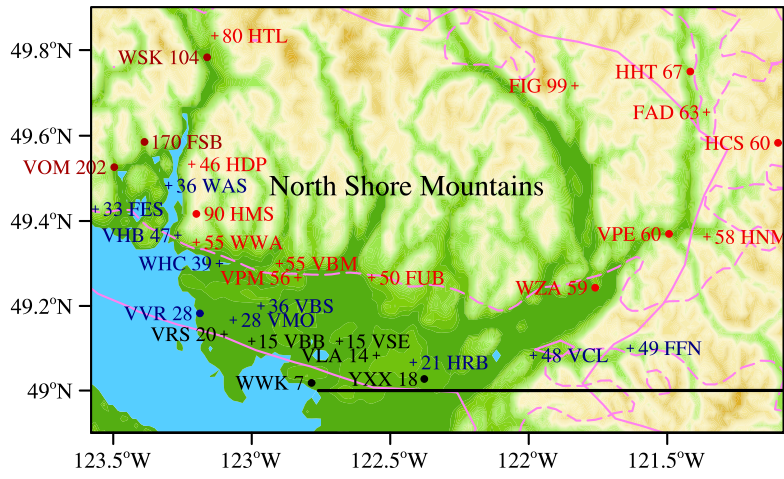

FIG. 11. (a) As in Fig. 10, but for the HRDPS-2.5km predictions. (b) Observed precipitation amounts ( $\mathrm{mm}$ ) in the Lower Mainland and Howe Sound area for the 24-h period ending at 1800 UTC 28 Jan 2016; the violet lines represent the 50-mm contours predicted by the RDPS-10km (solid) and the HRDPS-2.5km (dashed), respectively.

statistical measures for the objective model validation. The root mean-squared error (RMSE) and correlation (CORR) are two commonly used verification metrics, with the RMSE as an accuracy measure and the CORR as an association measure (Wilks 2011). The RMSE and CORR metrics for the original 24-h precipitation amounts are printed in blue italic. Since the precipitation distribution is highly skewed, these conventional metrics could be heavily influenced by the largest precipitation amounts. A cube root transformation of the 24-h precipitation amount can make the distribution more nearly symmetric (Stidd 1953; Mo et al. 2014; Fortin et al. 2018). The metrics based on this transformation are printed in green roman for reference. Our following discussions are based mainly on the original (blue italic) metrics. In addition, the model bias, defined as the prediction average minus the observation average, and the relative skill scores (RSS) defined in the appendix are also printed out to facilitate the model comparison.

It is shown in Fig. 13 that the heaviest rains fell on the windward slopes of Vancouver Island and the CoastCascade Mountains, and the HRDPS-2.5km performed 
(a) AWB-QPF vs observations

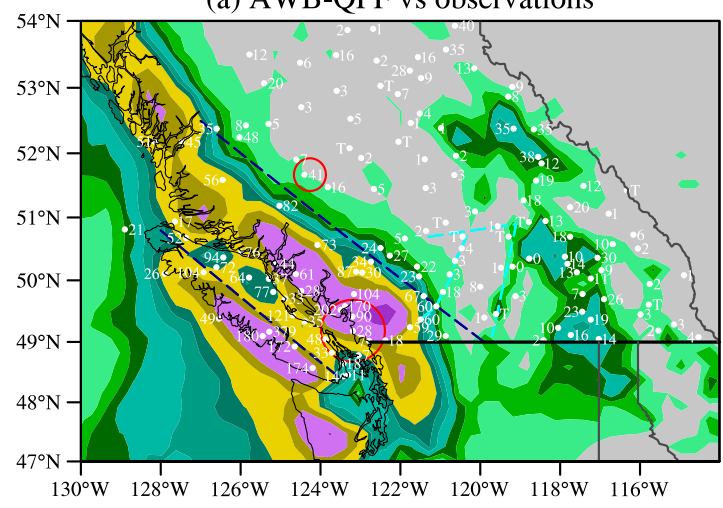

(b) HDC-QPF vs observations

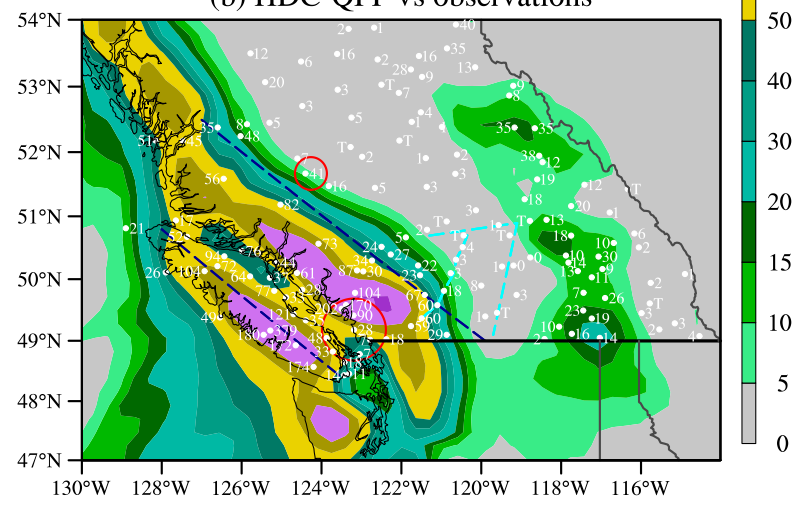

FIG. 12. Predicted (color shaded) and observed (white numbers) precipitation amounts $(\mathrm{mm})$ for the $24-\mathrm{h}$ period ending at 1800 UTC 28 Jan 2016. (a) The atmospheric water balance (AWB) scheme defined by Eq. (4), and (b) the hydrometeor drift calibration (HDC) defined by Eq. (5), both based on the GDPS-25km predictions initialized at 0000 UTC 27 Jan.

generally better than the other two lower-resolution models. Over the whole domain, the HRDPS-2.5km has the best validation scores, with the lowest RMSE of $24.1 \mathrm{~mm}$, the highest CORR of 0.85 , the lowest bias of $0.7 \mathrm{~mm}$, and the highest RSS of 0.63 . The RDPS- $10 \mathrm{~km}$ has a CORR of 0.70 , which is higher (and better) than that of the GDPS- $25 \mathrm{~km}(0.66)$. However, the GDPS- $25 \mathrm{~km}$ appears to perform better than the RDPS-10km in terms of RMSE ( 35.8 versus $39.4 \mathrm{~mm}$ ), bias ( 2.3 versus $2.7 \mathrm{~mm}$ ), transformed CORR (0.80 versus 0.76$)$, and RSS (0.17 versus 0.0$)$. This is somewhat unexpected, given that the RDPS-10km has the advantage of higher resolution. The right panel of Fig. 13b shows that the RDPS-10km tended to overforecast the higher precipitation amounts, thereby giving the worst RMSE and bias.

The RMSE and CORR metrics for the model performances on the windward and leeward slopes of Vancouver Island and the Coast-Cascade Mountains were also shown in Fig. 13. The 52 windward stations are located within the two distance intervals (with respect to the Vancouver Island crest) from -100 to $0 \mathrm{~km}$ and from
75 to $212 \mathrm{~km}$. The 41 leeward stations are located either within $75 \mathrm{~km}$ northeast of the Vancouver Island crest or within $100 \mathrm{~km}$ northeast of the Coast-Cascade Mountain crest. On the windward sides, the best performance was obtained by the HRDPS- $2.5 \mathrm{~km}$, and the worst by the GDPS-25km. The overforecasts by the RDPS-10km and the GDPS- $25 \mathrm{~km}$ can be easily identified near the $100-\mathrm{km}$ distance mark, which corresponds to the Lower Mainland area. On the other hand, all of the three models failed to predict the observed maximum amount of $379 \mathrm{~mm}(24 \mathrm{~h})^{-1}$ over Vancouver Island.

On the leeward sides, the GDPS-25km out-performed the two higher-resolution models. This result seems to be counterintuitive, given that the GDPS- $25 \mathrm{~km}$ QPF scheme has the lowest resolution and is incapable of handling the hydrometeor drift. A plausible explanation is that the low-resolution model can smooth windward heavy precipitation across the mountain crest, leading to an appearance of spillover onto the leeward slopes. In addition, the poor performance metrics of the HRDPS$2.5 \mathrm{~km}$ on the leeward slopes could also be related to a systematic bias in the MY2 microphysics scheme; we will come back to this problem in the next section.

Before ending this section, we would like to briefly compare Fig. 13c with Fig. 14, which shows the performances of the AWB and HDC schemes based on the GDPS-25km archived output. The large errors introduced from using hourly data to diagnose the precipitation rate led to that the AWB-QPFs (Fig. 14a) were less skillful than the original model QPFs (Fig. 13c). On the other hand, a slight improvement over the original QPFs was observed in the HDC-QPFs (Fig. 14b). Note that for these three forecasts as a group, the RSS of the GDPS- $25 \mathrm{~km}$ forecast in Fig. 13c shall be 0.38 (relative to the AWB scheme), which is smaller than that of the HDC scheme (0.42).

\section{The 16-18 January 2017 storm}

The AR-enhanced winter storm impacting $\mathrm{BC}$ on 26-28 January 2016 was analyzed in the previous section. A similar event on 16-18 January 2017 is briefly analyzed in this section. Here our main focus is on the observed and predicted orographic precipitation distributions, and how their main features resemble or differ from those seen in the 2016 storm.

\section{a. Synoptic features and orographic precipitation}

Figure 15 shows that a strong AR system moved through the Northeast Pacific during 16-18 January 2017. At 0000 UTC 16 January, a 965-hPa occluded cyclone in the Gulf of Alaska and a 1027-hPa subtropical high off the California coast provided a favorable 
(a) HRDPS-2.5km QPFs and observed amounts
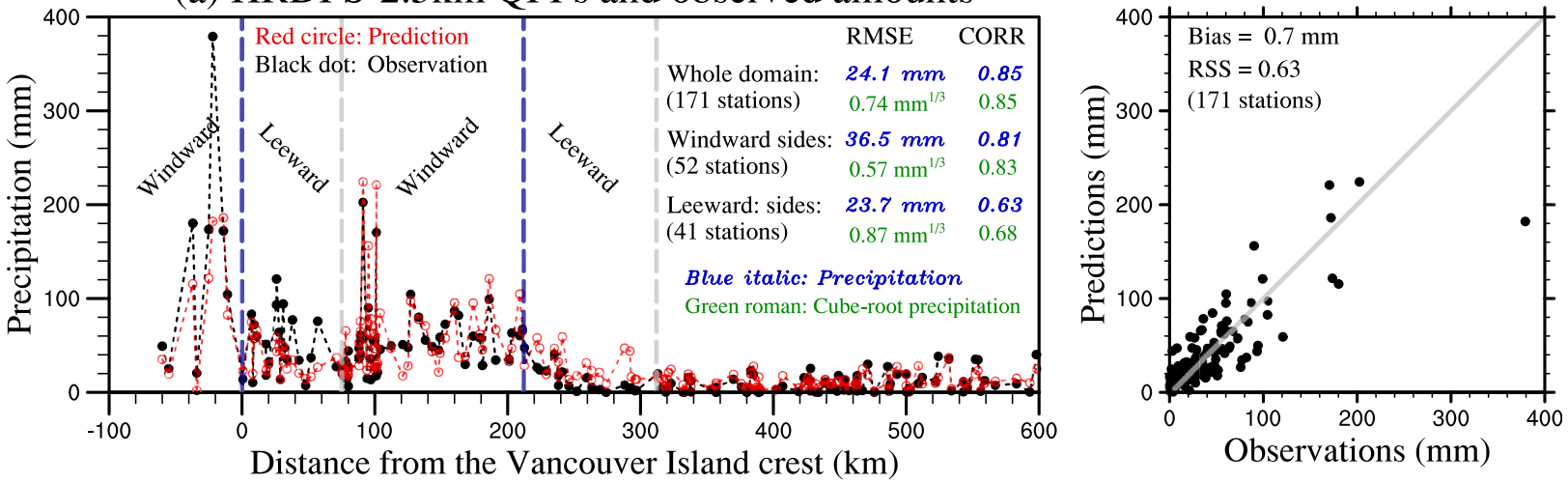

(b) RDPS-10km QPFs and observed amounts
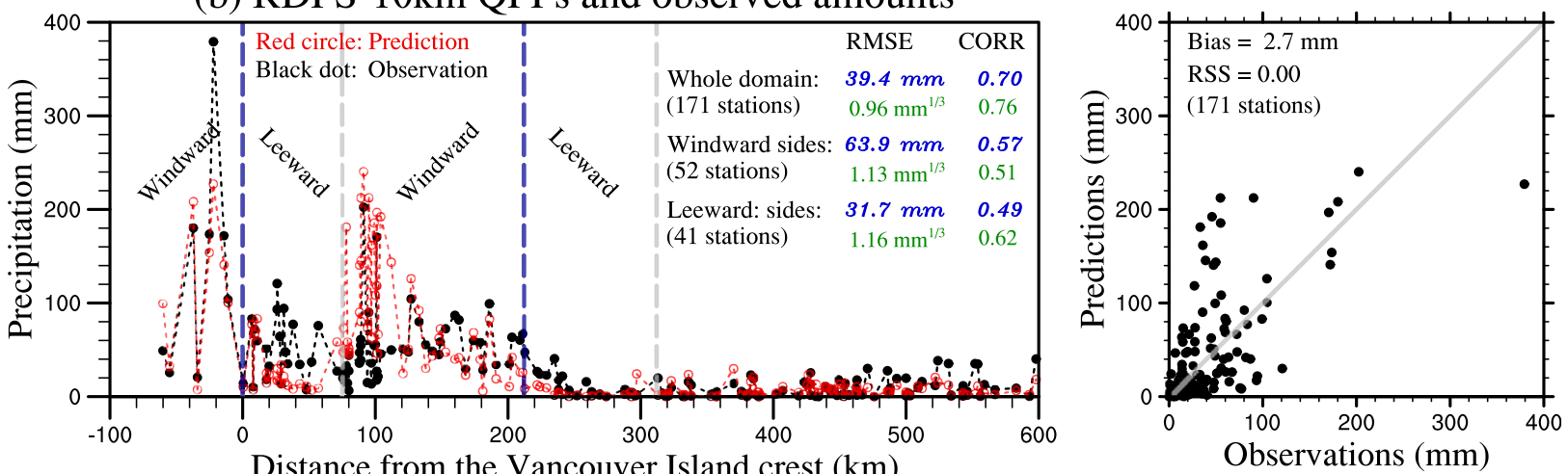

Distance from the Vancouver Island crest $(\mathrm{km})$
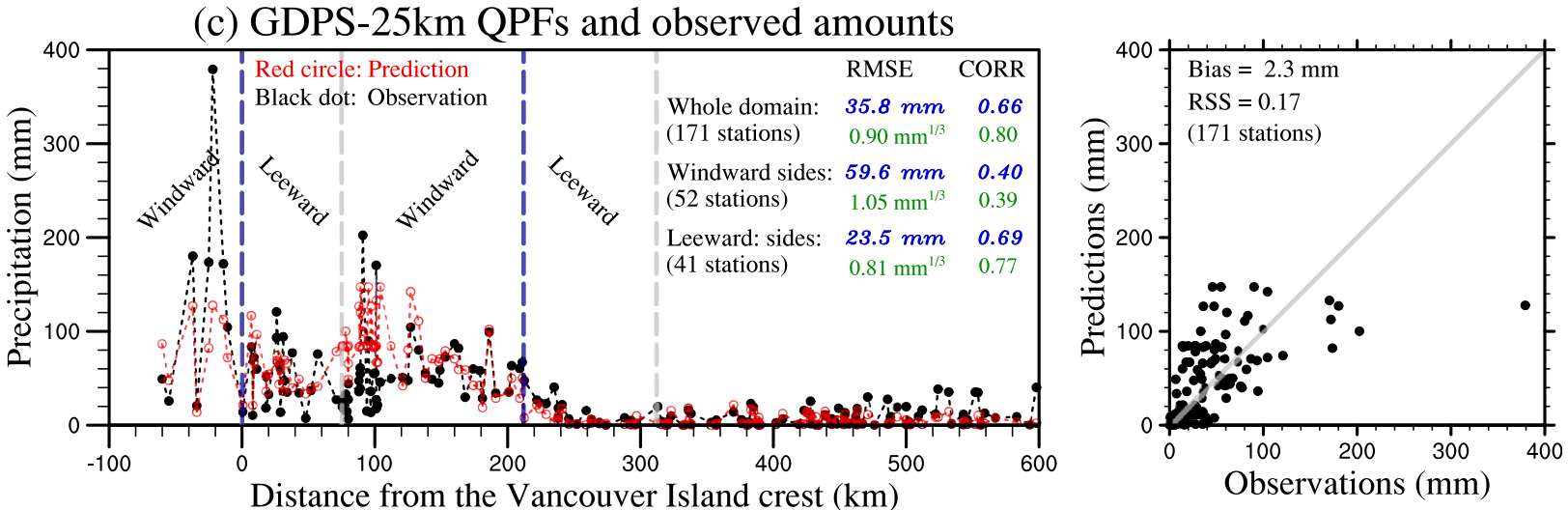

FIG. 13. Observations vs model predictions of precipitation amounts over the 24-h period ending at 1800 UTC 28 Jan 2016. All model runs were initialized at 0000 UTC 27 Jan. On the left-hand side, the predicted (red circle) and observed (black dot) precipitation amounts are plotted as a function of distance from the Vancouver Island crest, and the verification metrics of root mean squared error (RMSE) and correlation coefficient (CORR) are printed in the legend. These metrics are given for the 24-h precipitation (value in blue italic) and the cube-root of the 24-h precipitation (value in green roman) for each area (whole domain, windward sides, and leeward sides). A lower value of RMSE, or a higher value of CORR, indicates a better forecast. The two blue dashed lines represent the crests of the Vancouver Island Ranges and the Coast-Cascade Mountains. The two gray dashed lines mark the limits of the corresponding spillover zones. The windward/ leeward metrics are based on stations surround these two coastal ranges only. The right-hand side are scatterplots, where the bias is defined as the prediction mean minus the observation mean, and the relative skill score (RSS) is defined in the appendix.

environment for the AR development. Apparently, the AR had developed in the tropical western Pacific, and its center was seen in the central Pacific between $30^{\circ}$ and $40^{\circ} \mathrm{N}$ in Fig. 15a. Twelve hours later at 1200 UTC
(Fig. 15b), a 996-hPa cyclone had been developed on the northern flank of its leading edge. The AR made landfall around 1800 UTC 16 January (not shown). It maintained its maximum impact on the BC South 
(a) GDPS-25km AWB-QPFs and observed amounts
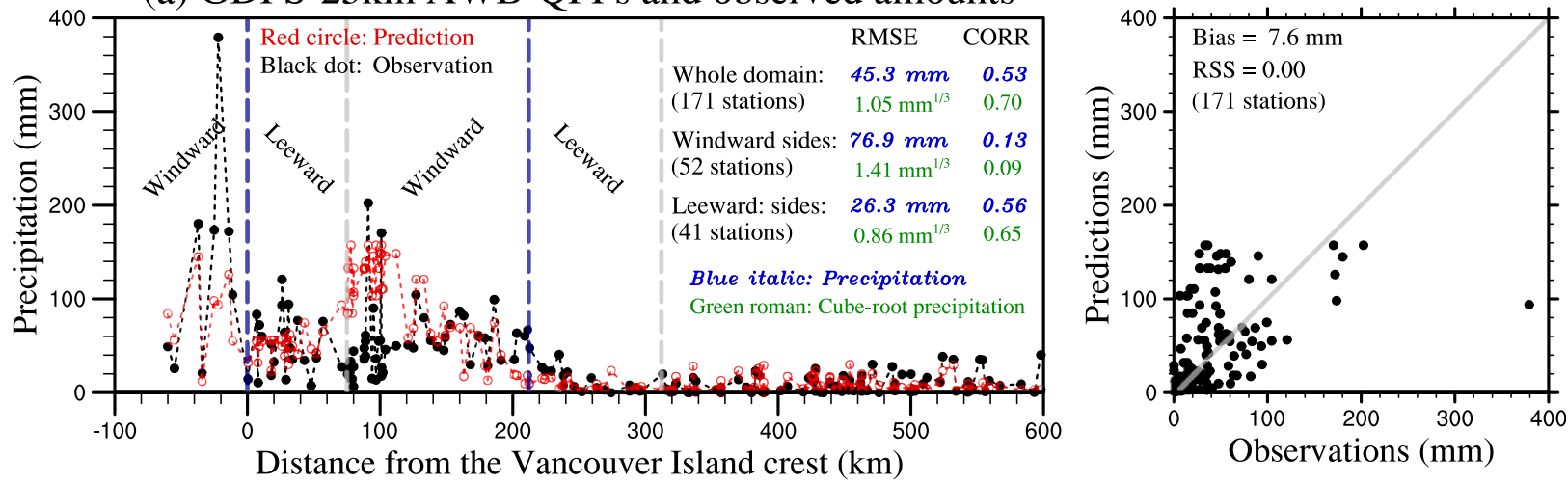

(b) GDPS-25km HDC-QPFs and observed amounts
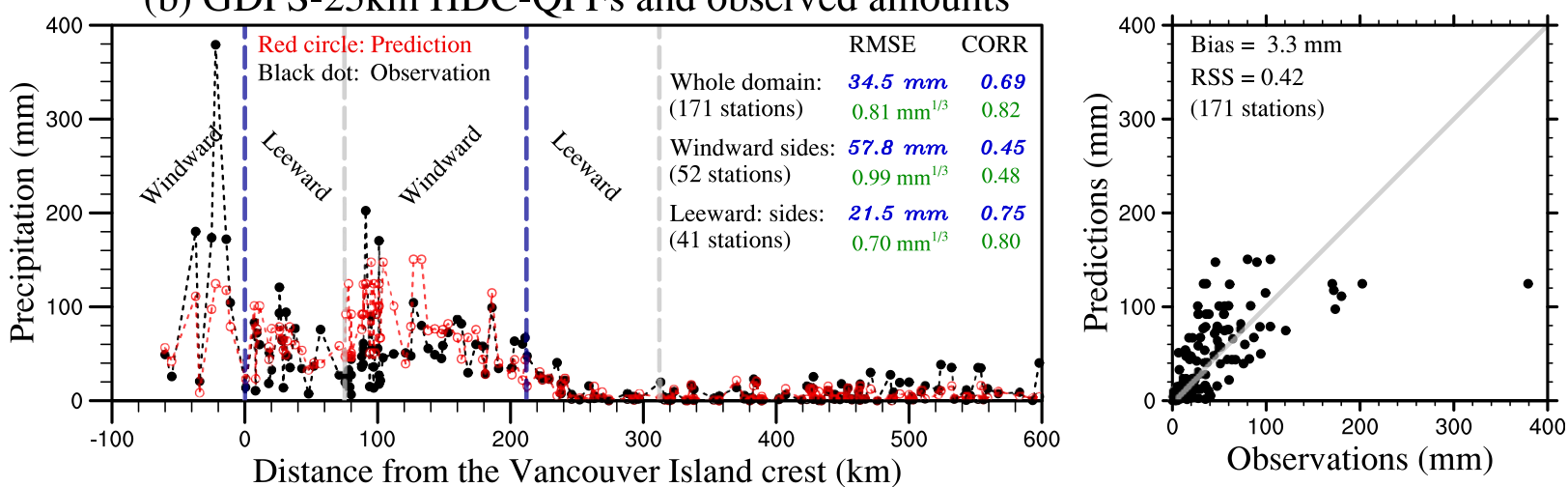

FIG. 14. As in Fig. 13, except for the QPFs predicted by (a) the GDPS-25km AWB scheme defined by Eq. (4), and (b) the GDPS-25km HDC scheme defined by Eq. (5).

Coast for the next $48 \mathrm{~h}$. Heavy orographic precipitation was observed and predicted by the NWP systems on the windward slopes of the Vancouver Island Ranges and the Coast-Cascade Mountains, as shown in Figs. 16 and 17.

Before the arrival of this AR system, western Canada was occupied by a cold and dry air mass. The collision of the AR with the cold air mass produced heavy precipitation and strong winds across coastal $\mathrm{BC}$, and freezing rain was observed in Whistler (cf. Geng et al. 2012). The precipitation potential of this storm was underestimated, and the Pacific Storm Prediction Centre only issued rainfall warnings for the Central Coast, Howe Sound, Metro Vancouver, and the Lower Fraser Valley. While all of these warnings were verified by observations, the warnings should have also covered the most heavy-precipitation prone region of West Vancouver Island, where several stations observed more than $100 \mathrm{~mm}$ in a 24-h period (see Fig. 16).

Because of the prestorm below-freezing conditions, the precipitation observations at some autostations are not reliable during the first few hours after the AR landfall. Even for the $24-h$ period starting at
1800 UTC 17 January, there were only 151 weather stations with reliable precipitation observations in the selected domain (as compared to the 171 stations in the previous event). Within this period, the maximum precipitation amount observed in $\mathrm{BC}$ was $322 \mathrm{~mm}$, which occurred (again) at the Effingham station $\left(\mathrm{FEH} ; 49.17^{\circ} \mathrm{N}, 125.28^{\circ} \mathrm{W}\right)$ in West Vancouver Island. As in the January 2016 storm, this 24-h amount is much higher than the $100 \mathrm{~mm}$ warning criterion for this region. A nearby highway station $\left(\mathrm{HKN} ; 49.10^{\circ} \mathrm{N}\right.$, $125.45^{\circ} \mathrm{W}$ ) only reported $110 \mathrm{~mm}$ in the same period. In the rain-shadow area of East Vancouver Island, a forestry station $\left(\mathrm{FBO} ; 49.44^{\circ} \mathrm{N}, 124.70^{\circ} \mathrm{W}\right)$ reported a 24-h amount of $66 \mathrm{~mm}$, exceeding the warning criterion of $50 \mathrm{~mm}$ for this region. Heavy precipitation was also observed in the Lower Mainland and Howe Sound areas (Fig. 17b); the local maximum 24-h amount of $124 \mathrm{~mm}$ was reported at two stations in Howe Sound.

\section{b. Hydrometeor drift and spillover effect}

As shown in Figs. 16 and 17, the general features of orographic precipitation were well predicted by the 
(a) 0000 UTC 16 Jan 2017

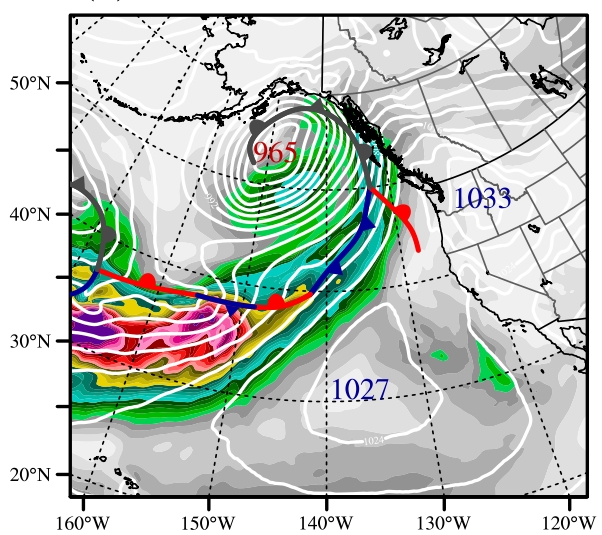

(c) 0000 UTC 17 Jan 2017

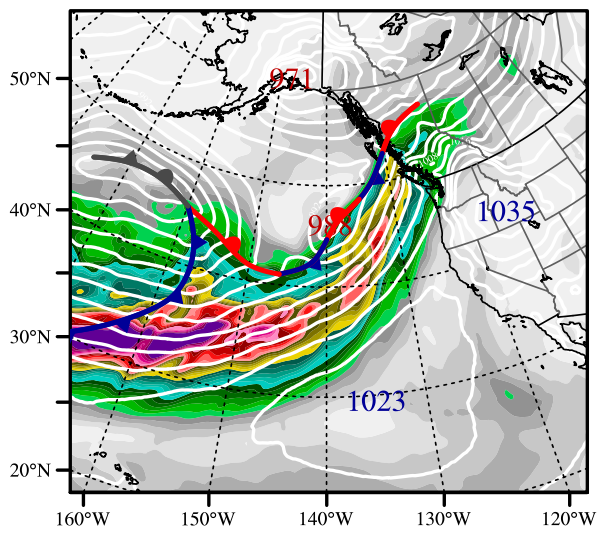

(e) 0000 UTC 18 Jan 2017

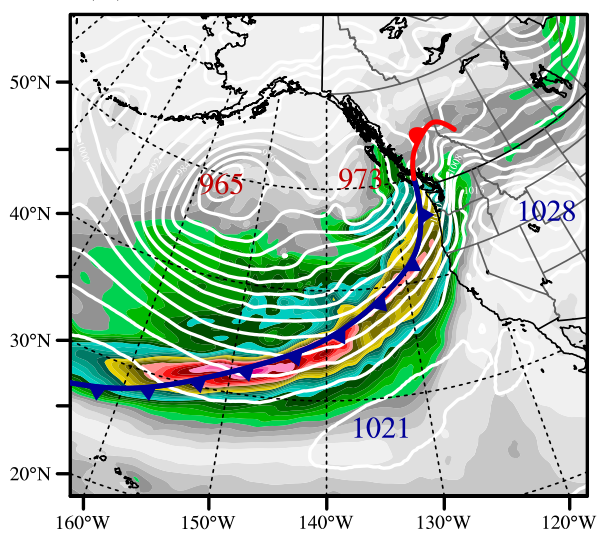

(b) 1200 UTC 16 Jan 2017

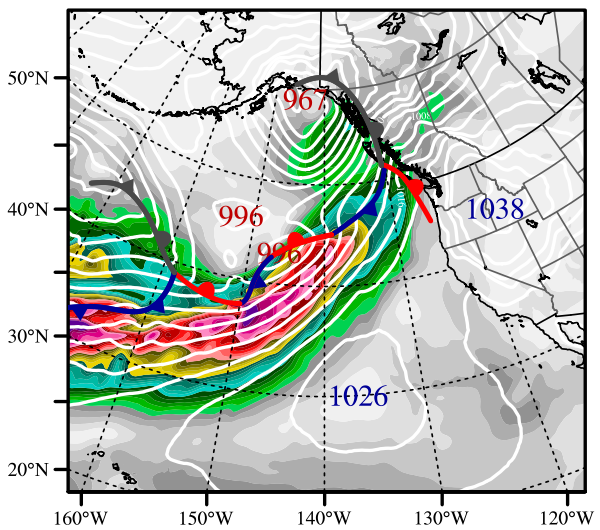

(d) 1200 UTC 17 Jan 2017

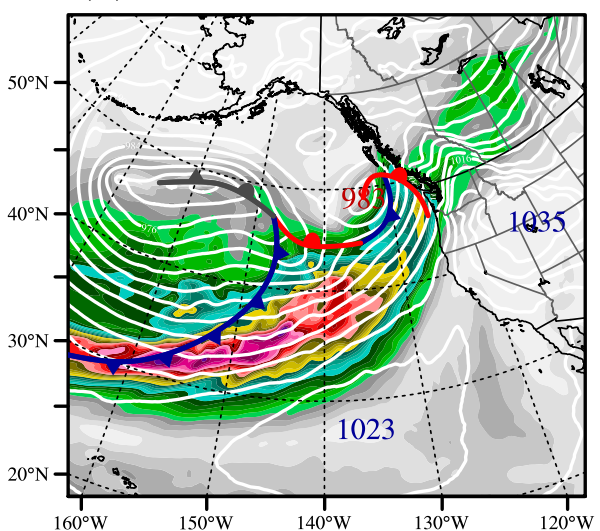

(f) 1200 UTC 18 Jan 2017

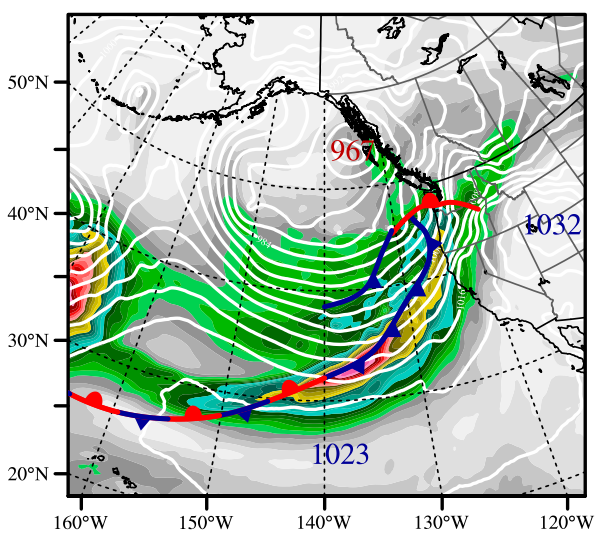

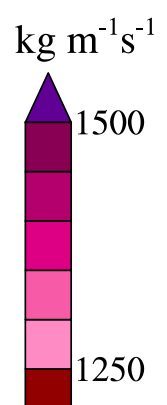

1000

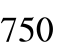

0

FIG. 15. The MSLP (white lines; contour interval: $4 \mathrm{hPa}$ ), the IVT (color shaded; $\mathrm{kg} \mathrm{m}^{-1} \mathrm{~s}^{-1}$ ), and the frontal analysis, based on the GDPS-25km analysis for the period from 0000 UTC 16 Jan to 1200 UTC 18 Jan 2017.

three NWP systems. However, both the GDPS-25km and RDPS-10km overpredicted the amounts to a large extent in the vicinity of Metro Vancouver. As shown in Fig. 17b, the observed values near the airport (VVR) and downtown (WHC) of Vancouver are $31 \mathrm{~mm}$ and $51 \mathrm{~mm}$, respectively. The predicted values by the GDPS$25 \mathrm{~km}$, the RDPS- $10 \mathrm{~km}$, and the HRDPS- $2.5 \mathrm{~km}$ for these two stations (VVR, WHC; mm) are $(91,91),(120$, $162)$, and $(19,42)$, respectively. The distance between these two stations is about $14 \mathrm{~km}$. Therefore, the GDPS$25 \mathrm{~km}$ predictions for them are the same. For operational meteorologists, the overpredictions by the GDPS$25 \mathrm{~km}$ and the RDPS $-10 \mathrm{~km}$ for the vicinity of Metro Vancouver represent a more serious problem than the 
(a) GDPS-25km predictions vs observations

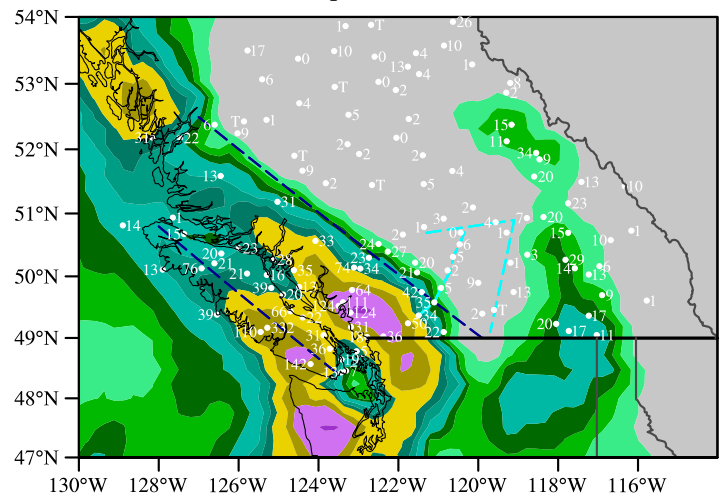

(b) RDPS-10km predictions vs observations

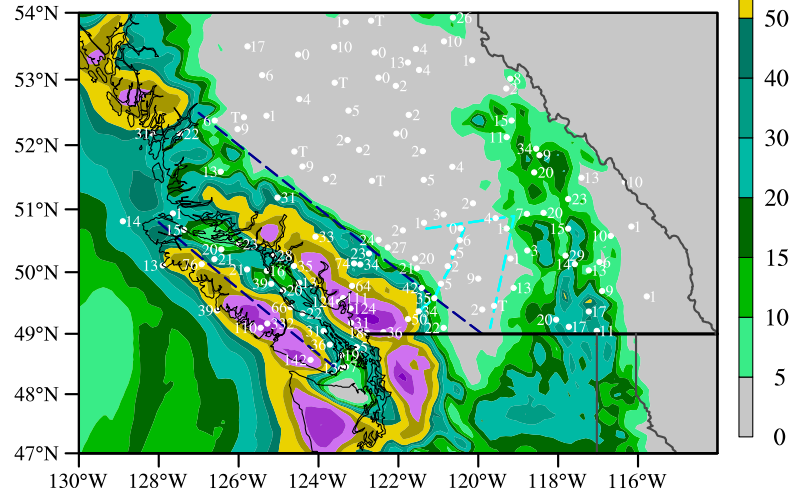

FIG. 16. Predicted (color shaded) and observed (white numbers) precipitation amounts for the 24-h period ending at 1800 UTC 18 Jan 2017. (a) The GDPS-25km and (b) the RDPS-10km, both runs initialized at 1200 UTC 17 Jan.

underpredictions by the HRDPS-2.5km. In Fig. 17b, the $50-\mathrm{mm}$ contours predicted by the HRDPS $-2.5 \mathrm{~km}$ and RDPS-10km are plotted in dashed and solid violet lines, respectively. The dashed lines are much better verified by the observations. As mentioned in the previous section, the better skill of the HRDPS$2.5 \mathrm{~km}$ for the AR-enhanced precipitation in this area is achieved mainly by its higher resolution as well as its capability to predict the hydrometeor drift effect.

However, the HRDPS-2.5km apparently overpredicted the hydrometeor drift effect into the lee of the Coast-Cascade Mountains for this case (Fig. 17a). The observations near the ridgeline in the eastern side and in the Okanagan Valley are generally lower than the predictions by the HRDPS- $2.5 \mathrm{~km}$, and higher than the predictions by the other two models. Over the Columbia and Rocky Mountains, the HRDPS-2.5km seems to have better skill than the RDPS-10km, which in turn is better than the GDPS-25km.

The objective verification metrics in Fig. 18 show that the HRDPS-2.5km performed much better than the two (a) HRDPS-2.5km predictions vs observations

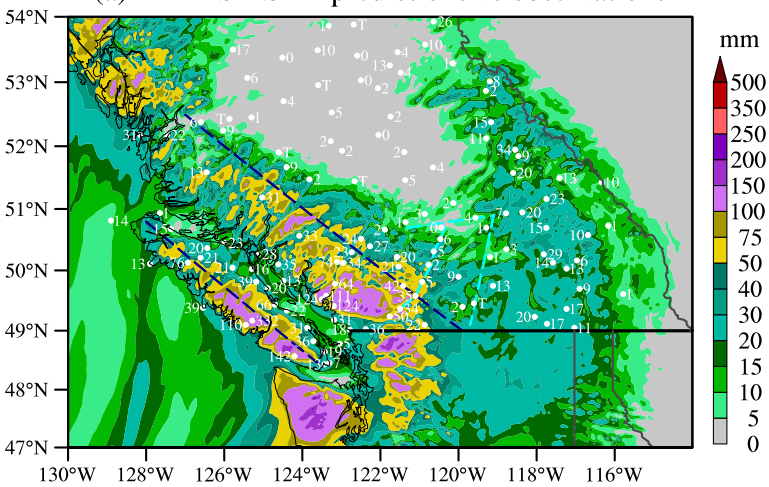

(b) Observations in Lower Mainland \& Howe Sound

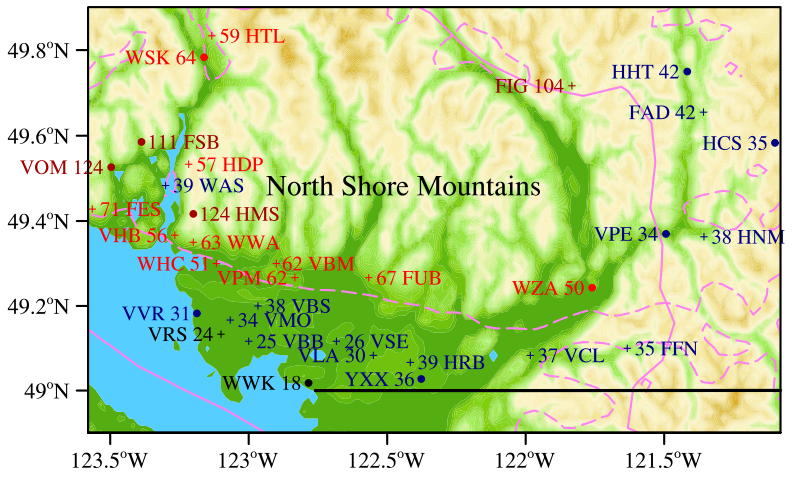

FIG. 17. (a) As in Fig. 16, but for the HRDPS-2.5km predictions initialized at 1200 UTC 17 Jan. (b) Observed precipitation amounts $(\mathrm{mm})$ in the Lower Mainland and Howe Sound area for the 24-h period ending at 1800 UTC 18 Jan 2017; the violet lines represent the $50-\mathrm{mm}$ contours predicted by the RDPS-10km (solid) and the HRDPS- $2.5 \mathrm{~km}$ (dashed), respectively.

coarser-resolution models over the whole domain as well as in the windward sides of the Vancouver Island Ranges and the Coast-Cascade Mountains. Here, the RDPS-10km achieved a worse RMSE score and only a slightly better CORR score than the GDPS$25 \mathrm{~km}$; the poorer RMSE score of the RDPS-10km was mainly due to overprediction in the coastal areas (Fig. 18b). Over the whole domain, the RSS of the HRDPS- $2.5 \mathrm{~km}$ is 0.79 , as compared to 0.0 of the RDPS-10km and 0.50 of the GDPS- $25 \mathrm{~km}$. In the leeward sides, however, the HRDPS $-2.5 \mathrm{~km}$ had the worst performance. This is the same problem identified in the previous section for the 27-28 January 2016 storm. It could be artificially enhanced by the insufficient density of observed data and the lack of a gauge correction for the solid precipitation in the observations for this storm under colder conditions. However, the main reason for this problem was likely caused by a systematic bias in the MY2 microphysics scheme (Milbrandt and Yau 2005a,b). The bias is linked to the fact that ice-phase particles are represented 
(a) HRDPS-2.5km QPFs and observed amounts
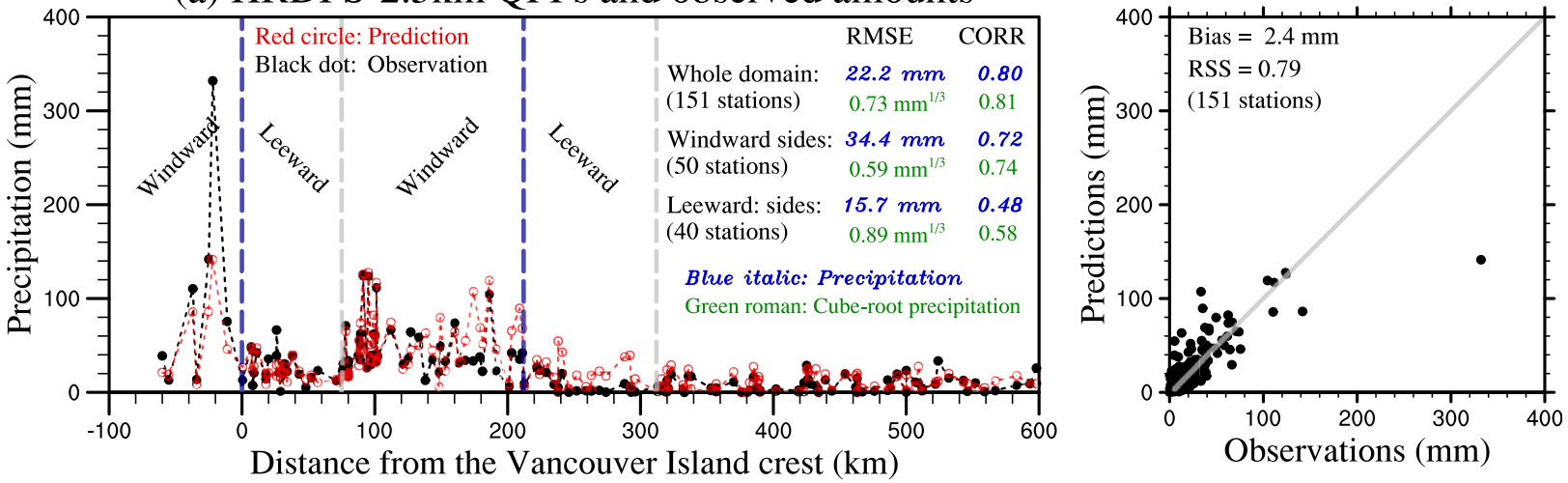

(b) RDPS-10km QPFs and observed amounts
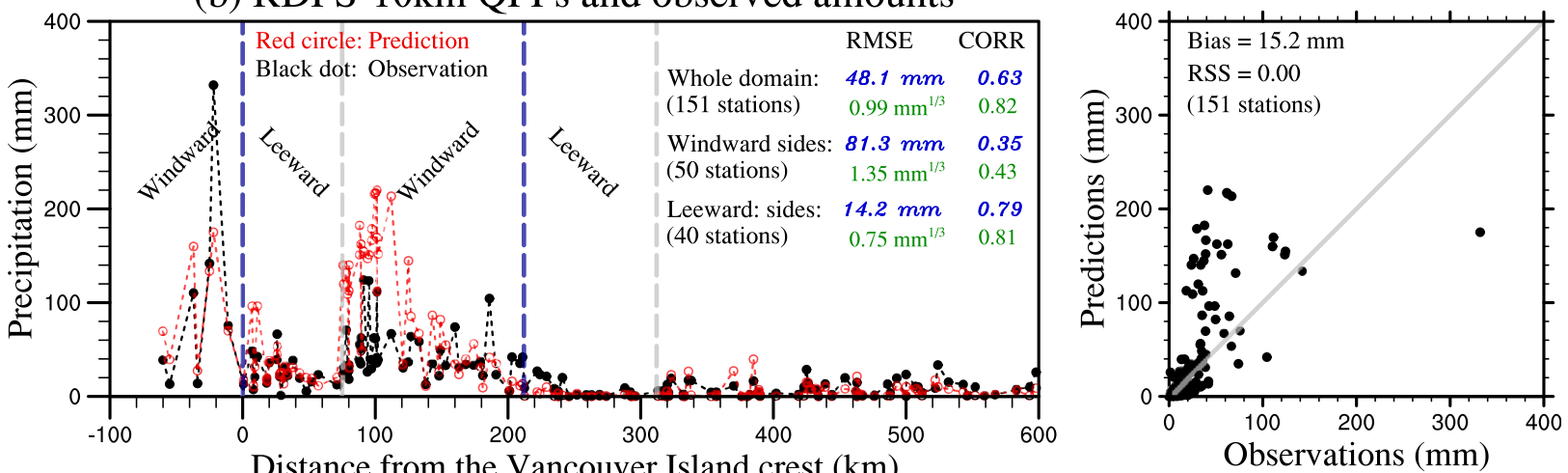

Distance from the Vancouver Island crest $(\mathrm{km})$

(c) GDPS-25km QPFs and observed amounts
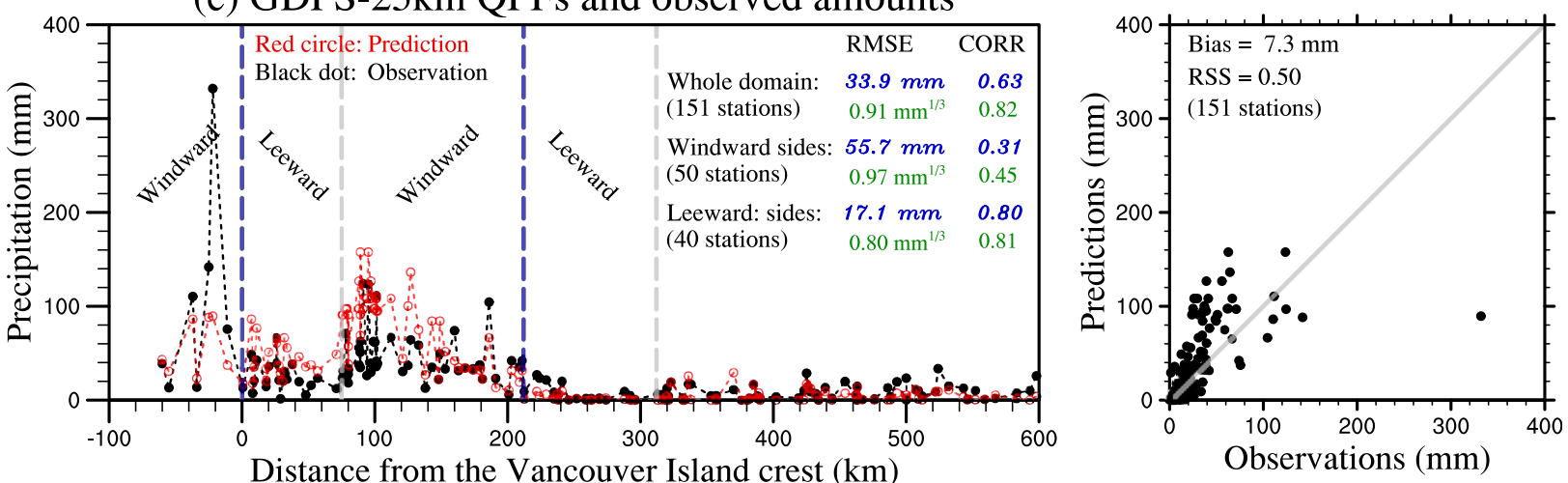

FIG. 18. As in Fig. 13, but for the precipitation amounts over the 24-h period ending at 1800 UTC 18 Jan 2017 , predicted by the three models initialized at 1200 UTC 17 Jan.

by predefined categories (as in most microphysics schemes). Essentially, in situations with light riming (e.g., when snow blows across the mountains and orographically enhanced lift creates pockets of liquid water), the scheme accounts for the mass growth of snow but not the increase in density and fall speed, unless the riming rate exceeds a threshold value such that snow is converted to graupel, which has a higher terminal fall speed. Such configurations have the potential to either allow slower-falling hydrometeors to remain aloft longer and be transported farther downstream, or conversion of graupel is too fast then the hydrometeors sediment too quickly and are not transported sufficiently far horizontally.

This inherent limitation in the MY2 scheme is overcome in the new P3 scheme (Morrison and Milbrandt 2015; Milbrandt and Morrison 2016) that was implemented into the operational HRDPS $2.5 \mathrm{~km}$ on 18 September 2018. With the P3 scheme, all ice-phase hydrometeors are represented by one or more "free" ice 


\section{(a) HRDPS-P3 QPFs and observed amounts}

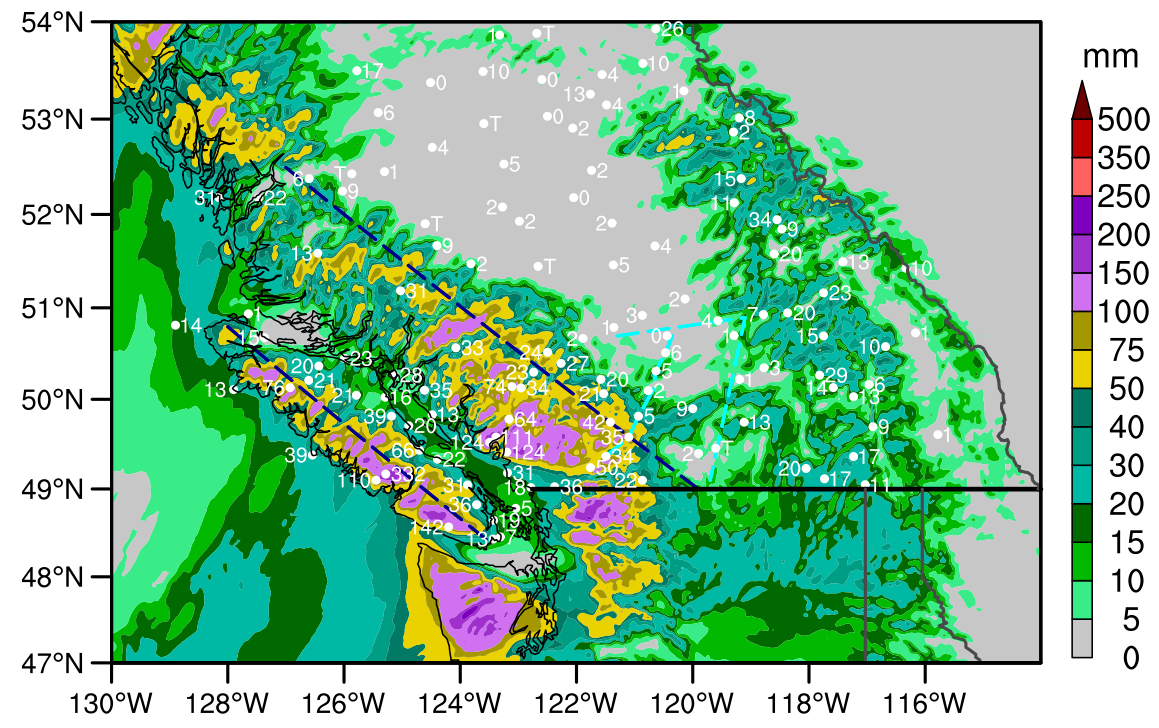

(b) Validation of the HRDPS-P3 QPFs
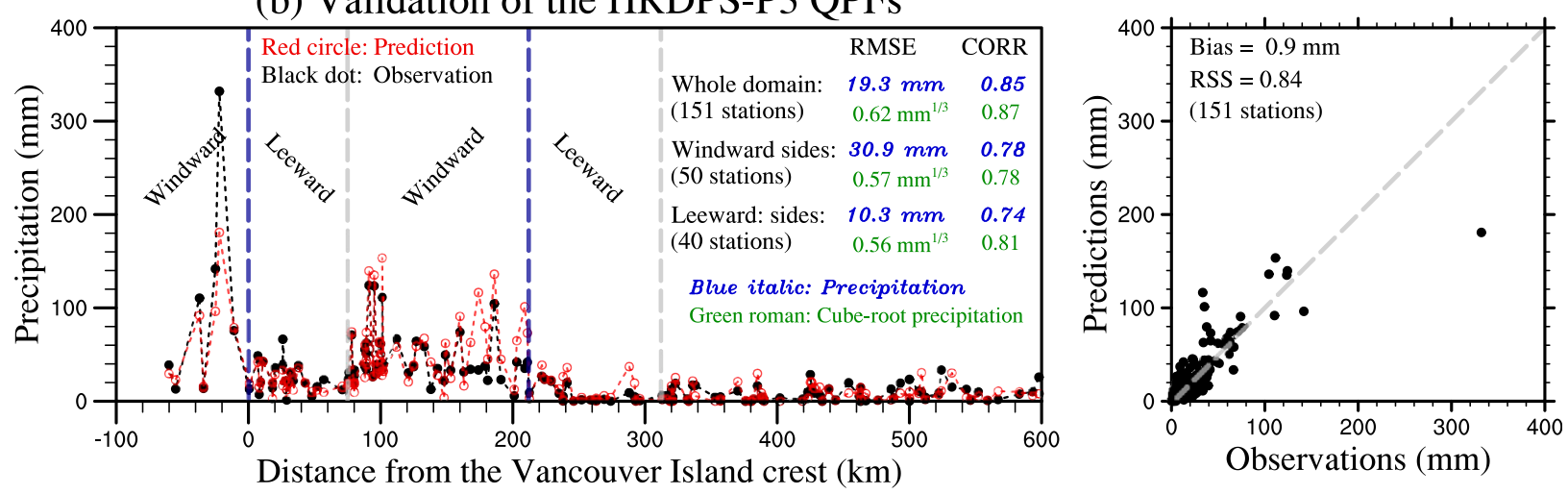

FIG. 19. (a) As in Fig. 17a, but for the QPFs from a parallel run of the HRDPS-2.5km with the new P3 microphysics scheme. (b) As in Fig. 18a, but for the QPFs of the HRDPS-2.5km P3 scheme. The RSS is also based on the RDPS-10km forecast in Fig. 18b.

categories whose physical properties evolve continuously in time and space (Morrison and Milbrandt 2015; Milbrandt and Morrison 2016). Figure 19 shows the distribution and validation of the 24-h QPFs of the P3 scheme for the January 2017 storm. As compared to the MY2 QPFs in Fig. 17a and their validation in Fig. 18a, the P3 scheme is more skillful over the whole domain, and it performs much better over the leeward sides, where the spillover of precipitation is overpredicted by the MY2. Note that the RMSE of the P3 on the leeward sides $(10.3 \mathrm{~mm})$ is also better than its RDPS-10km $(14.2 \mathrm{~mm})$ and GDPS- $25 \mathrm{~km}(17.1 \mathrm{~mm})$ counterparts. Morrison et al. (2015) noted a similar difference in behavior between MY2 and P3 for a case of orographically enhanced precipitation along the Oregon Cascades. Over the whole domain, the RSS of the P3 scheme (with the RDPS-10km forecast in Fig. $18 \mathrm{~b}$ as reference) is
0.84 , which is much higher than 0.50 achieved by the MY2 scheme.

\section{Discussion and conclusions}

Most extreme precipitation events that occur along the North American west coast are associated with winter atmospheric river (AR) storms. We have demonstrated with two case studies that predictions of the AR-enhanced orographic precipitation across the mountainous terrain in southern BC are very challenging, even with guidance from the state-of-the-art NWP systems. Based on our atmospheric water balance analysis, two key processes affecting the AR-enhanced orographic precipitation distribution were emphasized in this study: 1) the strong convergence of water vapor flux on the windward sides of mountain barriers, and 2) the combined 
effect of hydrometeor advection and convergence near the crests and leeward slopes of the mountains. When an AR makes landfall over complex terrain, the frictional convergence and the orographic lift can provide the necessary vertical motions to cause moist air to condense. The wind systems responsible for hydrometeor drift are usually fixed with respect to local orographic features, leading to heavy precipitation shifting toward the windward slopes and spilling over to the leeward side of the mountains. Atmospheric modelers and operational forecasters need to understand and consider all of these factors in order to predict orographic precipitation accurately and issue necessary warnings with useful lead times.

The three Canadian deterministic NWP systems use different precipitation schemes to provide QPF guidance to the operational forecasting communities. For reasons of computational cost, the GDPS-25km and the RDPS-10km use similar diagnostic schemes to calculate the QPFs. A detailed microphysics itself is more costly, and there are computational costs to the dynamics to advect (and diffuse) the hydrometeor tracer variables. Because these diagnostic schemes do not fully simulate the hydrometeor drift in the atmosphere, they can overpredict (underpredict) the precipitation amounts on the windward (leeward) side of mountain barriers. It was demonstrated in our two case studies that the hydrometeor drift had the most significant impact on the precipitation prediction in the Lower Mainland of $\mathrm{BC}$, where the population of the province is most concentrated. In particular, the overprediction of precipitation in the lowland area of Metro Vancouver by the diagnostic precipitation schemes could mislead operational forecasters into issuing rainfall warnings for the wrong locations. Also note that, because of their resolution limitations, these two models use a subgridscale orography parameterization scheme to represent gravity wave drag and low-level blocking effects, in order to reduce the winds when the flow encounters mountainous terrain (Zadra et al. 2003; Mailhot et al. 2006). This scheme depends heavily on the underlying geophysical fields. Even when the scheme is correctly implemented, it could produce an overestimation of the drag if amplitudes of the geophysical fields are too large, which could cause some QPF issues on the windward side of the mountains (A. Zadra 2018, personal communication).

On the other hand, the HRDPS-2.5km uses a prognostic microphysics scheme for precipitation, which has a mechanism to deal with hydrometeor drift and spillover of precipitation in complex terrain. This scheme showed much better skill predicting the precipitation distribution for the two AR-enhanced winter storms analyzed in this study. The distinctive benefits of using such kilometer-scale configurations over coarser-resolution systems in complex terrain lie not only in a better representation of topography, but also in their explicit accounting for the hydrometeor drift effects that can give rise to precipitation spillover. Our case studies indicate that there was a systematic bias in favor of overforecasting the spillover effect in the operational HRDPS- $2.5 \mathrm{~km}$ prior to 18 September 2018. With the implementation of the new P3 microphysics scheme, the excess hydrometeor drift problem in the current operational HRDPS has been significantly improved.

It may be reasonable to conclude that any NWP system that uses a diagnostic precipitation scheme will likely suffer from the same bias (i.e., excessive precipitation upstream and lack of spillover into the leeward side) as the Canadian GDPS and RDPS. In contrast, any system that uses a "traditional" microphysics schemes with predefined ice-phase categories (e.g., "snow," "graupel," etc.) will have improved precipitation forecasts in that regard, since it models hydrometeor drift. However, it will likely have a systematic bias of either underpredicting drift, if the scheme favors graupel, or overpredicting the drift (like the MY2), if the scheme favors snow (Garvert et al. 2005a,b; Milbrandt et al. 2008, 2010; Morrison et al. 2015).

We have also proposed two postprocessing schemes that have the potential to resolve the problem related to the lack of hydrometeor drift effect in the diagnostic precipitation schemes. The AWB scheme is based on the vertically integrated water balance equation, in which the precipitation rate can be decomposed into five interrelated components, including the convergence of condensed water due to hydrometeor drift in the atmosphere. Its application involves calculating each of the five components from the three-dimensional meteorological data, and then integrating the obtained precipitation rate with time to get the required QPFs. The HDC scheme is a simpler and more practical approach, which applies a hydrometeor drift calibration to the precipitation rate predicted by an NWP diagnostic precipitation scheme. We tested these two schemes using hourly model output of the GDPS-25km, and found some encouraging results from the HDC scheme. Further study is required to clarify the benefits and limitations of implementing these schemes for operational weather forecasts.

Acknowledgments. The authors are grateful to Curtis Mooney for his comprehensive internal review of an earlier version of the paper, and to Ayrton Zadra for helpful discussions on some model parameterization schemes. They thank Ford Doherty for maintaining an intelligent data archive system at the Pacific Storm 
Prediction Centre, Eric Meyer for useful information on the weather network of the BC Wildfire Service, and Rose-Ann Michael for the permission to include her photograph in Fig. 1. Supports from Matt Loney, Trevor Smith, Alison Dodd, Donald Talbot, Neil Taylor, Roxanne Vingarzan, and Chris Doyle are also highly appreciated. Constructive comments and suggestions from three anonymous reviewers greatly improved the manuscript.

\section{APPENDIX}

\section{Skill Scores for Forecast Comparisons}

\section{a. Mean-squared error}

The mean-squared error (MSE) is a commonly used measure of accuracy for field forecasts (Wilks 2011). It is defined as the average squared difference between the forecast and observation pairs:

$$
\operatorname{MSE}=\frac{1}{N} \sum_{n=1}^{N}\left(y_{n}-o_{n}\right)^{2}
$$

where $\left(y_{n}, o_{n}\right)$ is the $n$th of $N$ pairs of forecasts and observations. The MSE, or its squared root (RMSE = $\sqrt{\mathrm{MSE}})$, increases from zero for a perfect forecasts through larger positive values as the discrepancies between forecasts and observations increase. As compared to the MSE, the RMSE has the advantage that it retains the unit of the forecast variable, and therefore can be interpreted as a typical magnitude for forecast error.

\section{b. Climatological skill scores}

Skill scores can be designed to evaluate the forecast accuracy relative to a reference, such as a forecast based on climatology (Stanski et al. 1989; Wilks 2011). A climatological skill score (CSS) based on the MSE can be defined as follows (Murphy and Epstein 1989; Stewart 1990):

$\mathrm{CSS}=1-\frac{\mathrm{MSE}}{\mathrm{MSE}_{C}}, \quad \operatorname{MSE}_{C}=\frac{1}{N} \sum_{n=1}^{N}\left(\bar{o}_{n}-o_{n}\right)^{2}$,

where $\bar{o}_{n}$ is the climatological mean of the $n$th observations. This score is 1.0 for a perfect forecast, and 0.0 if the forecast is only as accurate as the climatology.

\section{c. Relative skill scores}

The QPF verifications in this study are based on the comparisons of precipitation amounts observed at 176 weather stations with their forecast values from different models. Some of these weather stations have been installed only for a short period, so that the climatological means of their observations are known only imperfectly. Therefore it is difficult to obtain a reliable CSS for each model from Eq. (A2). On the other hand, since the value of $\mathrm{MSE}_{C}$ is not affected by the choice of a particular model forecast, it can be expected that a model has a higher CSS than the other model if its MSE is smaller. Alternatively, for model comparison, we can define the relative skill scores (RSS) for a group of $K$ models as follows:

$$
\operatorname{RSS}(k)=1-\frac{\operatorname{MSE}(k)}{\operatorname{MSE}_{R}}, \quad k=1, \ldots, K,
$$

where $\operatorname{MSE}_{R}=\max \{\operatorname{MSE}(1), \ldots, \operatorname{MSE}(K)\}$ is chosen as the reference MSE. Therefore, the model with the highest MSE has the lowest RSS of 0.0, and the model with the lowest MSE has the highest RSS among the $K$ models.

\section{REFERENCES}

American Meteorological Society, 2019: Atmospheric river. Glossary of Meteorology, http://glossary.ametsoc.org/wiki/ Atmospheric_river.

Bélair, S., J. Mailhot, C. Girard, and P. Vaillancourt, 2005: Boundary layer and shallow cumulus clouds in a mediumrange forecast of a large-scale weather system. Mon. Wea. Rev., 133, 1938-1960, https://doi.org/10.1175/MWR2958.1.

Bell, J., and C. E. Harnett, 2016: Driver caught in flood. Times Colonist, 29 January, A4.

Benton, G. S., and M. A. Estoque, 1954: Water-vapor transfer over the North American continent. J. Meteor., 11, 462-477, https:// doi.org/10.1175/1520-0469(1954)011<0462:WVTOTN>2.0.CO;2.

Bližňák, V., Z. Sokol, and P. Zacharov, 2017: Nowcasting of deep convective clouds and heavy precipitation: Comparison study between NWP model simulation and extrapolation. Atmos. Res., 184, 24-34, https://doi.org/10.1016/j.atmosres.2016.10.003.

Brian, P., 2016: High tide, rain closes roads in Cowichan. Cowichan Valley Citizen, 29 January, 10, https://issuu.com/blackpress/ docs/i20160129044315167.

Browning, K. A., F. F. Hill, and C. W. Pardoe, 1974: Structure and mechanism of precipitation and the effect of orography in a wintertime warm sector. Quart. J. Roy. Meteor. Soc., 100, 309330, https://doi.org/10.1002/qj.49710042505.

_ C. W. Pardoe, and F. F. Hill, 1975: The nature of orographic rain at wintertime cold fronts. Quart. J. Roy. Meteor. Soc., 101, 333-352, https://doi.org/10.1002/qj.49710142815.

Brugman, M. M., and M. MacDonald, 2008: Westerly wind bursts affect avalanche cycles. Proc. 2008 Int. Snow Science Workshop, Whistler, BC, Canada, Montana State University, http:// arc.lib.montana.edu/snow-science/item.php?id=15.

Caron, J.-F., A. Zadra, D. Anselmo, T. Milewski, and A. Patoine, 2016: Regional Deterministic Prediction System (RDPS) update from version 4.2.0 to version 5.0.0. Part 1: Description of changes and forecast performance up to $48 \mathrm{~h}$. Tech. Note, Canadian Meteorological Centre, Dorval, Quebec, Canada, 47 pp., http://collaboration.cmc.ec.gc.ca/cmc/CMOI/product_guide/ docs/lib/technote_rdps-500_20160907_e.pdf.

Chater, A. M., and A. P. Sturman, 1998: Atmospheric conditions influencing the spillover of rainfall to lee of the southern Alps, 
New Zealand. Int. J. Climatol., 18, 77-92, https://doi.org/ 10.1002/(SICI)1097-0088(199801)18:1<77::AID-JOC218> 3.0.CO;2-M.

Cheng, C.-T., X.-Y. Wu, and K. W. Chau, 2005: Multiple criteria rainfall-runoff model calibration using a parallel genetic algorithm in a cluster of computers. Hydrol. Sci. J., 50, 1087, https://doi.org/10.1623/hysj.2005.50.6.1069.

Chu, Y.-H., T.-Y. Chen, and T.-H. Lin, 1997: An examination of the wind-driven effect on the drift of precipitation particles using the Chung-Li VHF radar. Radio Sci., 32, 957-966, https://doi.org/10.1029/97RS00057.

Colle, B. A., 2004: Sensitivity of orographic precipitation to changing ambient conditions and terrain geometries: An idealized modeling perspective. J. Atmos. Sci., 61, 588-606, https://doi.org/10.1175/1520-0469(2004)061<0588:SOOPTC > 2.0.CO;2

Cordeira, J. M., F. M. Ralph, and B. J. Moore, 2013: The development and evolution of two atmospheric rivers in proximity to western North Pacific tropical cyclones in October 2010. Mon. Wea. Rev., 141, 4234-4255, https://doi.org/10.1175/ MWR-D-13-00019.1.

Côté, J., S. Gravel, A. Méthot, A. Patoine, M. Roch, and A. Staniforth, 1998: The operational CMC-MRB global environmental multiscale (GEM) model. Part I: Design considerations and formulation. Mon. Wea. Rev., 126, 1373-1395, https://doi.org/10.1175/1520-0493(1998)126<1373:TOCMGE > 2.0.CO;2.

Cruickshank, A., 2019: A river in the sky: Atmospheric rivers are changing. Star Metro Vancouver, 31 May, p.1 \& p.6, http:// projects.thestar.com/climate-change-canada/british-columbia/.

Elliott, R. D., and E. L. Hovind, 1964: The water balance of orographic clouds. J. Appl. Meteor., 3, 235-239, https://doi.org/ 10.1175/1520-0450(1964)003<0235:TWBOOC $>2.0 . C O ; 2$.

Fletcher, R. D., 1951: Hydrometeorology in the United States. Compendium of Meteorology, T. F. Malone, Ed., Amer Meteor. Soc., 1033-1047.

Fortin, V., G. Roy, T. Stadnyk, K. Koenig, N. Gasset, and A. Mahidjiba, 2018: Ten years of science based on the Canadian precipitation analysis: A CaPA system overview and literature review. Atmos.-Ocean, 56, 178-196, https://doi.org/ 10.1080/07055900.2018.1474728.

Garvert, M. F., B. A. Colle, and C. F. Mass, 2005a: The 13-14 December 2001 IMPROVE-2 event. Part I: Synoptic and mesoscale evolution and comparison with a mesoscale model simulation. J. Atmos. Sci., 62, 3474-3492, https://doi.org/ 10.1175/JAS3549.1.

— , C. P. Woods, B. A. Colle, C. F. Mass, P. V. Hobbs, M. T. Stoelinga, and J. B. Wolfe, 2005b: The 13-14 December 2001 IMPROVE-2 event. Part II: Comparisons of MM5 model simulations of clouds and precipitation with observations. J. Atmos. Sci., 62, 3520-3534, https://doi.org/10.1175/JAS3551.1.

Geng, Q., R. Mo, M. Brugman, B. Snyder, J. Goosen, and G. Pearce, 2012: Interaction of an intense Pacific low pressure system with a strong arctic outbreak over British Columbia: Forecast challenges of the early December 2007 storm. Atmos.-Ocean 50, 95-108, https://doi.org/10.1080/07055900.2012.656261.

Girard, C., and Coauthors, 2014: Staggered vertical discretization of the Canadian Environmental Multiscale (GEM) mode using a coordinate of the log-hydrostatic-pressure type. Mon Wea. Rev., 142, 1183-1196, https://doi.org/10.1175/MWR-D13-00255.1.

Guan, B., and D. E. Waliser, 2015: Detection of atmospheric rivers: Evaluation and application of an algorithm for global studies.
J. Geophys. Res. Atmos., 120, 12 514-12 535, https://doi.org/ 10.1002/2015JD024257.

Hare, F. K., and M. K. Thomas, 1979: Climate Canada. Wiley Publishers of Canada Ltd., $230 \mathrm{pp}$.

Hill, F. F., K. A. Browning, and M. J. Bader, 1981: Radar and raingauge observations of orographic rain over south Wales. Quart. J. Roy. Meteor. Soc., 107, 643-670, https://doi.org/ 10.1002/qj.49710745312.

Hobbs, P. V., R. C. Easter, and A. B. Fraser, 1973: A theoretical study of the flow of air and fallout of solid precipitation over mountainous terrain. Part II: Microphysics. J. Atmos. Sci., 30, 813-823, https://doi.org/10.1175/1520-0469(1973)030<0813: ATSOTF $>2.0 . \mathrm{CO} ; 2$.

Ibbitt, R. P., R. D. Henderson, J. Copeland, and D. S. Wratt, 2000: Simulating mountain runoff with meso-scale weather model rainfall estimates: A New Zealand experience. J. Hydrol., 239, 19-32, https://doi.org/10.1016/S0022-1694(00)00351-6.

Kain, J. S., 2004: The Kain-Fritsch convective parameterization: An update. J. Appl. Meteor., 43, 170-181, https://doi.org/ 10.1175/1520-0450(2004)043<0170:TKCPAU > 2.0.CO;2.

Kaplan, M. L., R. K. Vellore, P. J. Marzette, and J. M. Lewis, 2012: The role of windward-side diabatic heating in Sierra Nevada spillover precipitation. J. Hydrometeor., 13, 1172-1194, https:// doi.org/10.1175/JHM-D-11-06.1.

Kuo, H.-L., 1974: Further studies of the parameterization of the influence of cumulus convection on large-scale flow. J. Atmos. Sci., 31, 1232-1240, https://doi.org/10.1175/1520-0469(1974) 031<1232:FSOTPO >2.0.CO;2.

Lange, O. S., 1998: The Wind Came All Ways: A Quest to Understand the Winds, Waves and Weather in the Georgia Basin. Environment Canada, $123 \mathrm{pp}$.

Li, J., Y. Chen, H. Wang, J. Qin, J. Li, and S. Chiao, 2017: Extending flood forecasting lead time in a large watershed by coupling WRF QPF with a distributed hydrological model. Hydrol. Earth Syst. Sci., 21, 1279-1294, https://doi.org/10.5194/ hess-21-1279-2017.

Lindsay, B., 2016: Five snowmobilers dead after large avalanche near McBridge. Vancouver Sun, 30 January, A19, http:// vancouversun.com/news/local-news/five-snowmobilers-dead-afterlarge-avalanche-near-mcbride.

Mahoney, K., and Coauthors, 2016: Understanding the role of atmospheric rivers in heavy precipitation in the Southeast United States. Mon. Wea. Rev., 144, 1617-1632, https://doi.org/10.1175/ MWR-D-15-0279.1.

Mailhot, J., and Coauthors, 2006: The 15-km version of the Canadian regional forecast system. Atmos.-Ocean, 44, 133-149, https:// doi.org/10.3137/ao.440202.

Mass, C., N. Johnson, M. Warner, and R. Vargas, 2015: Synoptic control of cross-barrier precipitation ratios for the Cascade Mountains. J. Hydrometeor., 16, 1014-1028, https://doi.org/ 10.1175/JHM-D-14-0149.1.

McCollor, D., and R. Stull, 2008: Hydrometeorological accuracy enhancement via postprocessing of numerical weather forecasts in complex terrain. Wea. Forecasting, 23, 131-144, https:// doi.org/10.1175/2007WAF2006107.1.

Medina, S., B. F. Smull, R. A. Houze Jr., and M. Steiner, 2005: Crossbarrier flow during orographic precipitation events: Results from MAP and IMPROVE. J. Atmos. Sci., 62, 3580-3598, https://doi.org/10.1175/JAS3554.1.

Milbrandt, J. A., and M. K. Yau, 2005a: A multimoment bulk microphysics parameterization. Part I: Analysis of the role of the spectral shape parameter. J. Atmos. Sci., 62, 3051-3064, https:// doi.org/10.1175/JAS3534.1. 
, and -2005 b: A multimoment bulk microphysics parameterization. Part II: A proposed three-moment closure and scheme description. J. Atmos. Sci., 62, 3065-3081, https://doi.org/ 10.1175/JAS3535.1.

, and H. Morrison, 2016: Parameterization of cloud microphysics based on the prediction of bulk ice particle properties. Part III: Introduction of multiple free categories. J. Atmos. Sci., 73, 975-995, https://doi.org/10.1175/JAS-D-15-0204.1.

— M. K. Yau, J. Mailhot, and S. Bélair, 2008: Simulation of an orographic precipitation event during IMPROVE-2. Part I: Evaluation of the control run using a triple-moment bulk microphysics scheme. Mon. Wea. Rev., 136, 3873-3893, https:// doi.org/10.1175/2008MWR2197.1.

$\ldots, \ldots, \ldots, \ldots$, and R. McTaggart-Cowan, 2010: Simulation of an orographic precipitation event during IMPROVE-2. Part II: Sensitivity to the number of moments in the bulk microphysics scheme. Mon. Wea. Rev., 138, 625-642, https:// doi.org/10.1175/2009MWR3121.1.

_ - J. Thériault, and R. Mo, 2014: Modeling the phase transition associated with melting snow in a 1D kinematic framework: Sensitivity to the microphysics. Pure Appl. Geophys., 171, 303-322, https://doi.org/10.1007/s00024-012-0552-y.

—, S. Bélair, M. Faucher, M. Vallée, M. L. Carrera, and A. Glazer, 2016: The Pan-Canadian high resolution $(2.5 \mathrm{~km})$ deterministic prediction system. Wea. Forecasting, 31, 1791-1816, https:// doi.org/10.1175/WAF-D-16-0035.1.

Mo, R., 2016: Atmospheric rivers in the Northeast Pacific: Pineapple Express. Meteorology Today: An Introduction to Weather, Climate, and the Environment, C. D. Ahrens, P. L. Jackson, and C. E. O. Jackson, Eds., Nelson Education Ltd., 360-361. , and H. Lin, 2019: Tropical-mid-latitude interactions: Case study of an inland-penetrating atmospheric river during a major winter storm over North America. Atmos.-Ocean, https://doi.org/10.1080/07055900.2019.1617673, in press.

_ , P. I. Joe, C. Doyle, and P. H. Whitfield, 2014: Verification of an ENSO-based long-range prediction of anomalous weather conditions during the Vancouver 2010 Olympics and Paralympics. Pure Appl. Geophys., 171, 323-336, https://doi.org/10.1007/ s00024-012-0523-3.

Moore, G. W. K., and G. Holdsworth, 2007: The 25-27 May 2005 Mount Logan storm. Part I: Observations and synoptic overview. J. Hydrometeor., 8, 590-606, https://doi.org/10.1175/ JHM586.1.

Morrison, H., and J. A. Milbrandt, 2015: Parameterization of cloud microphysics based on the prediction of bulk ice particle properties. Part I: Scheme description and idealized tests. J. Atmos. Sci., 72, 287-311, https://doi.org/10.1175/JAS-D-140065.1.

— — - G. H. Bryan, K. Ikeda, S. A. Tessendorf, and G. Thompson, 2015: Parameterization of cloud microphysics based on the prediction of bulk ice particle properties. Part II: Case study comparisons with observations and other schemes. J. Atmos. Sci., 72, 312-339, https://doi.org/10.1175/JAS-D-14-0066.1.

Murphy, A. H., and E. S. Epstein, 1989: Skill scores and correlation coefficients in model verification. Mon. Wea. Rev., 117, 572-582, https://doi.org/10.1175/1520-0493(1989)117<0572:SSACCI > 2.0.CO;2.

Newell, R. E., N. E. Newell, Y. Zhu, and C. Scott, 1992: Tropospheric rivers?-A pilot study. Geophys. Res. Lett., 19, 2401-2404, https://doi.org/10.1029/92GL02916.

Palmén, E., and C. W. Newton, 1969: Atmospheric Circulation Systems: Their Structure and Physical Interpretation. Academic Press, 603 pp.
Peixoto, J. P., 1973: Atmospheric vapor flux computations for hydrological purposes. Reports on WMO/IHD Projects, Rep. 20, World Meteorological Organization, Geneva, Switzerland, $83 \mathrm{pp}$.

Pudykiewicz, J., R. Benoit, and J. Mailhot, 1992: Inclusion and verification of a predictive cloud-water scheme in a regional numerical weather prediction model. Mon. Wea. Rev., 120, 612-626, https://doi.org/10.1175/1520-0493(1992)120<0612: IAVOAP $>2.0 . \mathrm{CO} ; 2$.

Qaddouri, A., C. Girard, L. Garand, A. Plante, and D. Anselmo, 2015: Global Deterministic Prediction System (GDPS) update from version 4.0.1 to version 5.0.0 - Yin-Yang grid configuration. Tech. Note, Canadian Meteorological Centre, Dorval, Quebec, Canada, 68 pp., http://collaboration.cmc.ec.gc.ca/cmc/cmoi/ product_guide/docs/lib/technote_gdps-500_20151215_e.pdf.

Ralph, F. M., P. J. Neiman, D. E. Kingsmill, P. O. G. Persson, A. B. White, E. T. Strem, E. D. Andrews, and R. C. Antweiler, 2003: The impact of a prominent rain shadow on flooding in California's Santa Cruz Mountains: A CALJET case study and sensitivity to the ENSO cycle. J. Hydrometeor., 4, 1243-1264, https://doi.org/10.1175/1525-7541(2003)004<1243:TIOAPR > 2.0.CO;2.

,-- , and G. A. Wick, 2004: Satellite and CALJET aircraft observations of atmospheric rivers over the eastern North Pacific Ocean during the winter of 1997/98. Mon. Wea. Rev., 132, 1721-1745, https://doi.org/10.1175/1520-0493(2004)132<1721: SACAOO $>2.0 . \mathrm{CO} ; 2$.

— , and Coauthors, 2017: Atmospheric rivers emerge as a global science and applications focus. Bull. Amer. Meteor. Soc., 98, 1969-1973, https://doi.org/10.1175/BAMS-D-16-0262.1.

_ J. J. Rutz, J. M. Cordeira, M. Dettinger, M. Anderson, D. Reynolds, L. J. Schick, and C. Smallcomb, 2019: A scale to characterize the strength and impacts of atmospheric rivers. Bull. Amer. Meteor. Soc., 100, 269-289, https://doi.org/ 10.1175/BAMS-D-18-0023.1.

Rasmussen, R., and Coauthors, 2012: How well are we measuring snow: The NOAA/FAA/NCAR winter precipitation test bed. Bull. Amer. Meteor. Soc., 93, 811-829, https://doi.org/10.1175/ BAMS-D-11-00052.1.

Robertson, D. E., D. L. Shrestha, and Q. J. Wang, 2013: Postprocessing rainfall forecasts from numerical weather prediction models for short-term streamflow forecasting. Hydrol. Earth Syst. Sci., 17, 3587-3603, https://doi.org/10.5194/hess-173587-2013.

Rutz, J. J., W. J. Steenburgh, and F. M. Ralph, 2014: Climatological characteristics of atmospheric rivers and their inland penetration over the western United States. Mon. Wea. Rev., 142, 905-921, https://doi.org/10.1175/MWR-D-13-00168.1.

Siler, N., and G. Roe, 2014: How will orographic precipitation respond to surface warming? An idealized thermodynamic perspective. Geophys. Res. Lett., 41, 2606-2613, https:// doi.org/10.1002/2013GL059095.

— shadows? Insights from case studies in the Cascades and idealized simulations. J. Atmos. Sci., 73, 4077-4099, https:// doi.org/10.1175/JAS-D-15-0371.1.

— G. Roe, and D. Durran, 2013: On the dynamical causes of variability in the rain-shadow effect: A case study of the Washington Cascades. J. Hydrometeor., 14, 122-139, https:// doi.org/10.1175/JHM-D-12-045.1.

Sinclair, M. R., D. S. Wratt, R. D. Henderson, and W. R. Gray, 1997: Factors affecting the distribution and spillover of precipitation in the Southern Alps of New Zealand-A case 
study. J. Appl. Meteor., 36, 428-442, https://doi.org/10.1175/ 1520-0450(1997)036<0428:FATDAS > 2.0.CO;2.

Stanski, H. R., L. J. Wilson, and W. R. Burrows, 1989: Survey of common verification methods in meteorology. World Weather Watch Tech. Rep. 8, WMO Tech. Doc. 358, World Meteorological Organization, $114 \mathrm{pp}$

Stewart, T. R., 1990: A decomposition of the correlation coefficient and its use in analyzing forecasting skill. Wea. Forecasting, 5, 661-666, https://doi.org/10.1175/1520-0434(1990)005<0661: ADOTCC $>2.0 . \mathrm{CO} ; 2$.

Stidd, C. K., 1953: Cube-root-normal precipitation distributions. Eos, Trans. Amer. Geophys. Union, 34, 31-35, https://doi.org/ 10.1029/TR034i001p00031.

Stoelinga, M. T., R. E. Stewart, G. Thompson, and J. M. Thériault, 2013: Microphysical processes within winter orographic cloud and precipitation systems. Mountain Weather Research and Forecasting: Recent Progress and Current Challenges, F. K. Chow, S. F. J. De Wekker, and B. J. Snyder, Eds., Springer, 345-408, https://doi.org/10.1007/978-94-007-4098-3_7.

Sundqvist, H., 1978: A parameterization scheme for nonconvective condensation including prediction of cloud water content. Quart. J. Roy. Meteor. Soc., 104, 677-690, https:// doi.org/10.1002/qj.49710444110.

Taormina, R., K.-W. Chau, and B. Sivakumar, 2015: Neural network river forecasting through baseflow separation and binary-coded swarm optimization. J. Hydrol., 529, 1788-1797, https://doi.org/10.1016/j.jhydrol.2015.08.008.

Titian, D., 2016: RCMP take their chances on flooded road at Zeballos. Ha-Shilth-Sa (Canada's oldest first nation's newspaper), 18 February, 12, http://www.hashilthsa.com/news/ 2016-01-28/rcmp-take-their-chances-flooded-road-zeballos.

Trenberth, K. E., and C. J. Guillemot, 1998: Evaluation of the atmospheric moisture and hydrological cycle in the NCEP/NCAR reanalyses. Climate Dyn., 14, 213-231, https:// doi.org/10.1007/s003820050219.

Tuller, S. E., 1987: The spatial distribution of heavy precipitation in the Greater Victoria region. Climatol. Bull., 21 (1), 3-18.

Underwood, S. J., M. L. Kaplan, and K. C. King, 2009: The role of upstream midtropospheric circulations in the Sierra Nevada enabling leeside (spillover) precipitation. Part I: A synopticscale analysis of spillover precipitation and flooding in a leeside basin. J. Hydrometeor., 10, 1309-1326, https://doi.org/ 10.1175/2009JHM1105.1.
Wastl, C., and G. Zängl, 2010: Mountain-valley precipitation differences in the northern Alps: an exemplary high-resolution modeling study. Meteor. Atmos. Phys., 108, 29-42, https:// doi.org/10.1007/s00703-010-0083-y.

Wick, G. A., 2014: Implementation and initial application of an atmospheric river detection tool based on integrated vapor transport. 2014 Fall Meeting, San Francisco, CA, Amer. Geophys. Union, Abstract A34E-06.

Wilks, D. S., 2011: Statistical Methods in the Atmospheric Sciences. 3rd ed. International Geophysics Series, Vol. 100, Academic Press, $704 \mathrm{pp}$.

Wu, C. L., and K. W. Chau, 2011: Rainfall-runoff modeling using artificial neural network coupled with singular spectrum analysis. J. Hydrol., 399, 394-409, https://doi.org/10.1016/ j.jhydrol.2011.01.017.

Wulfmeyer, V., and Coauthors, 2011: The Convective and Orographically-induced Precipitation Study (COPS): The scientific strategy, the field phase, and research highlights. Quart. J. Roy. Meteor. Soc., 137, 3-30, https://doi.org/10.1002/ qj.752.

Zadra, A., M. Roch, S. Laroche, and M. Charron, 2003: The subgrid-scale orographic blocking parametrization of the GEM model. Atmos.-Ocean, 41, 155-170, https://doi.org/ 10.3137/ao.410204.

Zängl, G., 2005: The impact of lee-side stratification on the spatial distribution of orographic precipitation. Quart. J. Roy. Meteor. Soc., 131, 1075-1091, https://doi.org/10.1256/qj.04.118.

_ 2007: Interaction between dynamics and cloud microphysics in orographic precipitation enhancement: A high-resolution modeling study of two North Alpine heavy-precipitation events. Mon. Wea. Rev., 135, 2817-2840, https://doi.org/ 10.1175/MWR3445.1.

, and M. Hornsteiner, 2007: The exceptional Alpine south foehn event of 14-16 November 2002: A case study. Meteor. Atmos. Phys., 98, 217-238, https://doi.org/10.1007/s00703-0060257-9.

Zhu, Y., and R. E. Newell, 1994: Atmospheric rivers and bombs. Geophys. Res. Lett., 21, 1999-2002, https://doi.org/10.1029/ 94GL01710.

_, and _- 1998: A proposed algorithm for moisture fluxes from atmospheric rivers. Mon. Wea. Rev., 126, 725-735, https://doi.org/10.1175/1520-0493(1998)126<0725:APAFMF> 2.0.CO;2. 